\title{
THE EFFECT OF THE PATIENT PROTECTION AND AFFORDABLE CARE ACT MEDICAID EXPANSIONS ON FINANCIAL WELLBEING
}

\author{
Luojia $\mathrm{Hu}$ \\ Robert Kaestner \\ Bhashkar Mazumder \\ Sarah Miller \\ Ashley Wong \\ Working Paper 22170 \\ http://www.nber.org/papers/w22170 \\ NATIONAL BUREAU OF ECONOMIC RESEARCH \\ 1050 Massachusetts Avenue \\ Cambridge, MA 02138 \\ April 2016, Revised February 2018
}

This work was supported by the National Institutes of Health [1R01HD081129-01]. The views expressed here do not represent the views of the Federal Reserve Bank of Chicago, the Federal Reserve System, or the National Bureau of Economic Research. We thank Sharada Dharmasankar for her excellent research assistance. We also thank the editor and three referees for helpful comments.

NBER working papers are circulated for discussion and comment purposes. They have not been peer-reviewed or been subject to the review by the NBER Board of Directors that accompanies official NBER publications.

(C) 2016 by Luojia Hu, Robert Kaestner, Bhashkar Mazumder, Sarah Miller, and Ashley Wong. All rights reserved. Short sections of text, not to exceed two paragraphs, may be quoted without explicit permission provided that full credit, including $(\subset)$ notice, is given to the source. 
The Effect of the Patient Protection and Affordable Care Act Medicaid Expansions on Financial Wellbeing Luojia Hu, Robert Kaestner, Bhashkar Mazumder, Sarah Miller, and Ashley Wong NBER Working Paper No. 22170 April 2016, Revised February 2018

JEL No. H20,I13,I38

\begin{abstract}
$\underline{\text { ABSTRACT }}$
We examine the effect of the Medicaid expansions under the 2010 Patient Protection and Affordable Care Act (ACA) on consumer financial outcomes using data from a major credit reporting agency for a large, national sample of adults. We employ the synthetic control method to compare individuals living in states that expanded Medicaid to those that did not. We find that the Medicaid expansions significantly reduced the number of unpaid bills and the amount of debt sent to third-party collection agencies among those residing in zip codes with the highest share of low-income, uninsured individuals. Our estimates imply a reduction in collection balances of approximately $\$ 1,140$ among those who gain Medicaid coverage due to the ACA. Our findings suggest that the ACA Medicaid expansions had important financial impacts beyond health care use.

Luojia $\mathrm{Hu}$

Federal Reserve Bank of Chicago

230 S. LaSalle Street

Chicago, IL 60604

lhu@frbchi.org

Robert Kaestner

Department of Economics

University of Illinois at Chicago

601 S. Morgan Street

Chicago, IL 60607

and Institute of Government and Public Affairs

and also NBER

kaestner.robert@gmail.com

Bhashkar Mazumder

Federal Reserve Bank of Chicago

230 S. LaSalle Street

Chicago, IL 60604

bhash.mazumder@gmail.com

Sarah Miller

Ross School of Business

University of Michigan

701 Tappan Street

Ann Arbor, MI 48109

and NBER

mille@umich.edu

Ashley Wong

Federal Reserve Bank of Chicago

230 S. LaSalle Street

Chicago, IL 60604

ashley.wong816@gmail.com
\end{abstract}

An online appendix is available at http://www.nber.org/data-appendix/w22170 


\section{Introduction}

In 2010, President Barack Obama signed the Patient Protection and Affordable Care Act (ACA) into law, which included a provision to expand Medicaid eligibility to low-income adults, many of whom were previously ineligible. A major motivation for this expansion was to provide financial security to individuals if they experience a sudden deterioration in their health and cannot afford to pay for their medical expenses.

Indeed, the financial consequences of not having health insurance can be severe for individuals who become seriously ill or injured. According to data from the 2012 Medical Expenditure Panel Survey (MEPS), the annual cost of inpatient care for a person aged 18 to 64 who was hospitalized was approximately $\$ 15,000$, and the annual cost of all types of care for that person was $\$ 25,000$. Studies using survey data suggest that the uninsured often have difficulty paying medical expenses, become delinquent on their medical and non-medical bills, and are more likely to be contacted by collection agencies. ${ }^{1}$ Dobkin et al. (2017) find that uninsured individuals who become hospitalized experience a host of financial setbacks over the next four years including reduced access to credit, a 170\% increase in unpaid medical bills, and a more than doubling in the likelihood of filing for bankruptcy.

These statistics highlight how the Medicaid expansions under the ACA could play an important role in providing low-income individuals with financial protection by improving their ability to pay their medical expenses. Additionally, expanded health care coverage may also have indirect effects on financial wellbeing. Access to health insurance and a reduction in medical expenses has the potential to improve access to credit markets, increase savings, and facilitate consumption of other goods and

\footnotetext{
${ }^{1}$ Cunningham (2008) reported that $34 \%$ of those without medical insurance had trouble paying their medical bills, and among this group, $62 \%$ had been contacted by a collection agency. Doty et al. (2008) found that $62 \%$ of persons that had trouble paying medical bills reported having more than \$2,000 of outstanding medical bills, while $20 \%$ reported having more than $\$ 8,000$ in outstanding medical bills. Finkelstein et al. (2012) reported that approximately $60 \%$ of participants in the control group of the Oregon Health Insurance Experiment currently owe money for a medical expense, and 36\% indicated that they borrowed money or skipped other bills to pay for medical expenses. Nuñez et al (2016) show that medical debt incurred during periods of un-insurance spills over into other forms of debt.
} 
services. These other channels can potentially have salutary effects on the wellbeing of low-income individuals. $^{2}$

Despite the potentially important role that publicly provided health insurance plays in the financial wellbeing of low-income individuals, only three studies have evaluated the role of Medicaid on consumer financial wellbeing. Gross and Notowidigdo (2011) examined the effect of Medicaid eligibility expansions in the 1990s, which were mostly for children, on bankruptcy. They found that increasing Medicaid eligibility by 10 percentage points reduced personal bankruptcy by about $8 \%$. The Oregon Health Insurance Experiment (Baicker et al., 2013; Finkelstein et al., 2012) found that Medicaid coverage of low-income adults in Oregon reduced the likelihood of borrowing money or skipping bills to pay for medical care by $44 \%$ and reduced the probability of having a medical collection by $23 \%$. Finally, a recent study by Brevoort et al. (2017) examined the effect of the ACA Medicaid expansions on new medical debt. Estimates from this study indicate that the expansions completely eliminated new medical debt for those who obtained Medicaid. Other studies have evaluated the effects of other types of health insurance coverage on financial outcomes and have also documented substantial improvements in financial wellbeing (Barcellos and Jacobson 2015; Mazumder and Miller 2016; Dobkin et al. 2017).

We extend this literature by evaluating the effect of the expansion of Medicaid under the ACA to low-income adults on consumer financial wellbeing. Although originally intended to apply to all states, in 2012 the U.S. Supreme Court decision in the National Federation of Independent Business v. Sebelius case made the Medicaid expansions optional for states. As of the end of 2015, 29 states and the District of Columbia had chosen to expand Medicaid coverage (at least in some form) and 21 states had opted not to expand Medicaid coverage. ${ }^{3}$ Rates of health insurance coverage have improved substantially more in the

\footnotetext{
${ }^{2}$ Doty et al. (2008) found that among the uninsured who were paying off medical bills, $47 \%$ stated that they had exhausted their savings and 40\% reported that they had foregone other necessities such as food, heat, or rent in order to pay medical bills. Leininger et al. (2010) reported that SCHIP expansions were associated with increased consumption and savings. In contrast, Gruber and Yelowitz (1996) found that savings and asset accumulation were reduced as Medicaid eligibility expanded in late 1980s and early 1990s.

${ }^{3}$ As we discuss below, for our analysis, the classification of treatment and control states differs from this simple distinction, and we consider various groupings of states based on their implementation dates.
} 
states that offer expanded Medicaid coverage than in those that do not (Black and Cohen 2015; Kaestner et al., 2017; Sommers 2014; Wherry and Miller 2016; Miller and Wherry 2017), and total Medicaid enrollment in these states increased by 12.3 million between 2013 and 2015 (Centers for Medicare \& Medicaid Services, 2015). We exploit the variation in Medicaid eligibility and coverage induced by these state-level policy choices to estimate the effect of the Medicaid expansions on individual financial outcomes. We use the synthetic control approach (Abadie et al., 2010) to address concerns about the potential non-randomness of states’ decisions to expand Medicaid.

As far as we are aware, ours is the first national study that evaluates how public health insurance coverage for non-elderly adults affects financial wellbeing. We use data from a large, nationallyrepresentative sample of credit reports, the Federal Reserve Bank of New York Consumer Credit Panel/Equifax (CCP) dataset to conduct our analysis. The CCP data contain timely information on a random sample of the credit reports of approximately 38 million adults in the United States each quarter (covering about $17 \%$ of the adult population) and provide many indicators of financial wellbeing. We focus on a few, broad measures of financial wellbeing where the effects of the 2014 Medicaid expansion could potentially be detected during our sample period. Specifically, we examine credit score, total debt, total debt past due, credit card debt, credit card debt past due, the number of bills sent to collections, the total balance outstanding in collections, and bankruptcy.

Our main finding is that Medicaid expansions that began in 2014 significantly reduced the number of unpaid bills and the amount of debt sent to third-party collection agencies among people living in zip codes that are most likely affected by the expansions. Our baseline intention-to-treat (ITT) estimates indicate that the Medicaid expansions are associated with a decrease in the amount of unpaid balances in collections of between $\$ 65$ and $\$ 88$. This effect is an average over the entire sample and includes many individuals who did not obtain Medicaid insurance coverage through the expansion. Rescaling this estimate based on the fraction of the target population who were likely to have obtained insurance coverage yields estimates of the effect of obtaining Medicaid (i.e., treatment on the treated) on collection balances of approximately $\$ 1,140$. These estimates indicate a substantial improvement in 
financial well-being for individuals who gained coverage. We also found some suggestive evidence that the Medicaid expansion reduced the total amount of consumer debt. While we do not find evidence of a reduction in other type of delinquencies, the improvement in financial well-being may provide benefits beyond the direct benefit of eliminating medical debt, which is an interesting area for future study. The reduction in unpaid bills also implies that the benefits of expanding Medicaid likely include hospitals and creditors that serve the low-income population.

\section{Framework for the Analysis}

\section{Conceptual Framework}

Medicaid provides health insurance coverage at no, or very low, cost to the enrollee. Given the low income of individuals who became eligible for Medicaid through the ACA ( $<138 \%$ of federal poverty), even relatively minor, unexpected medical expenses can represent a substantial fraction of their total income, and more serious illness may be catastrophic financially for them. Consequently, we hypothesize that the financial protection provided by Medicaid for low-income individuals should largely eliminate most of their significant medical expenses, as well as reduce delinquencies and other indicators of financial distress that are the focus of our study.

While the Medicaid expansion will decrease the amount of unpaid medical bills and delinquencies, the effects of gaining Medicaid eligibility on other debt and borrowing are theoretically ambiguous. The financial protection afforded by Medicaid coverage should reduce the need for lowincome individuals to borrow to smooth consumption when medical issues arise. Thus, Medicaid has the potential to decrease a person's borrowing and total debt. Alternatively, Medicaid may reduce the need for individuals to save for precautionary reasons, which may increase consumption and borrowing. In this case, the Medicaid expansions would be associated with increases in total debt for low-income individuals. In sum, the effect of the Medicaid expansions on measures of debt are ambiguous and an empirical question. 
Although our analysis focuses on measuring the effect of the Medicaid expansions on individuals, the potential benefits of the Medicaid expansions extend to hospitals (healthcare providers) and consumer financial services companies. Research has shown that improving the capacity of low-income, uninsured individuals to pay for medical care through Medicaid expansions can improve hospital profitability (Garthwaite, Gross, and Notowidigdo 2018; Nikpay et al., 2017). Presumably, improving repayment rates would also lower the costs of providing credit, which would benefit consumer-finance firms and the customers they serve. Finally, we note that even if the financial benefits accrue entirely to hospitals or other creditors (i.e., medical bills would never have been otherwise paid), Medicaid recipients likely gain a psychological benefit as a result of not having to interact with debt collectors or worry about medical bills.

Research Design

To study the effect of Medicaid on consumer, financial wellbeing, we use variation in Medicaid eligibility and coverage stemming from the expansion of Medicaid under the ACA, which targeted nonelderly adults with incomes below $138 \%$ of the Federal Poverty Level (FPL). The fact that not all states expanded Medicaid, as originally intended by the ACA, provides plausibly exogenous variation in health insurance coverage among low-income adults that can be used to identify estimates of the effect of Medicaid eligibility on consumer financial wellbeing.

There is a large literature that examined the effect of prior Medicaid expansions on a variety of outcomes and most of these studies used a difference-in-differences (DiD) research design. The implementation of the DiD method is straightforward and consists of a comparison of changes in outcomes before and after the expansion of Medicaid for individuals in states that did and did not expand Medicaid. Individuals living in states that expanded Medicaid are the treatment group and those in states that did not expand Medicaid are the comparison group. The key assumption underlying the validity of the $\mathrm{DiD}$ approach is that, in the absence of the ACA Medicaid expansions, changes in the financial 
indicators of wellbeing would be the same for persons in states that did and did not expand Medicaid. This assumption is often referred to as the "parallel trends" assumption.

The parallel trends assumption is often difficult to maintain in practice and preliminary analyses of our data indicated some violations of the assumption. Specifically, we find evidence that year-to-year changes in some of our outcomes differed between the expansion and non-expansion states prior to the ACA Medicaid expansions (see results reported in Appendix Table 11). ${ }^{4}$ The failure of the parallel trends assumption is perhaps unsurprising given that the DiD approach assumes that all non-expanding states (e.g., Texas and Florida), provide a good comparison for states that did expand Medicaid (e.g., Illinois and California). Therefore, instead of the usual DiD approach, we implement the synthetic control method of Abadie et al. (2010), which uses a matching procedure to create a synthetic comparison (control) group composed of a weighted average of observations from states that did not expand Medicaid. The Abadie et al. (2010) approach is in the same spirit of DiD because the estimate of the effect of Medicaid on consumer financial outcomes is obtained by taking the difference in means between treated states and a weighted average of non-treated states (i.e., synthetic control), but only in the post-intervention period of 2014 and 2015. The Abadie et al. (2010) approach assumes that pre-intervention differences between treatment and synthetic control groups are zero. Indeed, the approach's objective is to select a comparison group in such a way as to minimize the pre-intervention differences in means between the treatment group and the control group.

The key to the Abadie et al. (2010) approach is the selection of the weights that are used to construct the synthetic control group, or counterfactual outcome. Following Abadie et al. (2010), we choose weights that minimize the differences between the pre-Medicaid expansion mean values of the dependent variable and covariates of the treatment and control groups. The argument underlying this approach is that, if the pre-expansion means are equal between treated and untreated states, then the post-

\footnotetext{
${ }^{4}$ For purposes of comparison, we also report the difference-in-differences estimates corresponding to our main analysis in Appendix Table 10.
} 
Medicaid expansion difference between the groups is likely to represent a valid estimate of the effect of the Medicaid expansion. An advantage of the Abadie et al. (2010) approach is that the closeness of the match can be assessed easily (e.g., graphically), and the weight for each potential comparison state is provided. $^{5}$

There are a variety of ways to select weights that are used to construct the synthetic comparison group and it is not obvious that there is one correct method. Therefore, we use two approaches. Our first approach minimizes the difference between the pre-expansion values of the dependent variable and covariates of treated and untreated states for each pre-expansion period. As an alternative, we also minimize the difference between the average value of the dependent variable during the pre-expansion period, the 2013 value of the dependent variable, and each pre-expansion value of the covariates. ${ }^{6}$

Once the weights are selected and the synthetic comparison group is constructed, the estimates of the effect of Medicaid on financial wellbeing are derived by taking the post-2014 (Medicaid expansion) mean difference between the outcome in the treatment group (combined into one unit) and in the synthetic comparison group. Inferences for these estimates are derived from permutation tests (randomization inference). These tests consist of performing the analysis 1,000 times, but each time using randomlyselected states to form the treatment group. For each of these 1,000 "random" estimates, we estimate the post-2014 difference in outcomes as if the treatment indicator had been correctly assigned to the expansion states. We then calculate the share of "randomized" estimates that are larger in absolute value than the estimate obtained using the actual treatment group assignments. This share is the $p$-value corresponding to a two-sided test. This method captures the probability of obtaining estimates as large as the actual treatment group's estimate even when treatment is randomly assigned. The approach is the same as that used by Abadie et al. (2010), and the same or similar techniques have been implemented in

\footnotetext{
${ }^{5}$ Only states with positive weights are used to construct the synthetic comparison group.

${ }^{6}$ See Kaul et al. (2015) for an analysis of the potential consequences of different approaches; matching on each preperiod value of the dependent variable eliminates the influence of covariates. In our analysis, the method of choosing weights does not materially affect estimates.
} 
other applications of the synthetic control method, such as Barone and Mocetti (2014), Billmeier and Nannicini (2013), and Eren and Ozbeklik (2016). ${ }^{7}$

As we describe below, we use a sample selected on the basis of location to identify individuals who are more likely to have been treated due to the Medicaid expansion. However, this sample still includes many people not affected by the Medicaid expansions. Therefore, our estimates are intention-totreat (ITT) effects. ITT estimates are useful and provide policy- and theory-relevant evidence of the effect of a state's expansion of Medicaid on the financial wellbeing of the low-income inhabitants. We also provide estimates of the effect of Medicaid coverage on individual financial wellbeing (i.e., treatment on treated) by rescaling the ITT estimates using "first stage” estimates of the proportion of individuals in our sample likely to have gained Medicaid coverage.

\section{Data}

\section{American Community Survey}

We use data from the 2010-2015 American Community Survey (ACS) to estimate the impact of the Medicaid expansions on health insurance coverage. This analysis constitutes the "first stage” of our analysis. Although other studies have used these data to show that the Medicaid expansions increased insurance coverage (e.g., Buchmueller et. al. 2016; Kaestner et al. 2017), we replicate their results using the synthetic control method so that the first stage is estimated in a fashion consistent with our reduced form estimates that measure the effect of Medicaid expansions on financial well-being. In order to focus on the most-affected geographic regions, we restrict our analysis to include only individuals living in

\footnotetext{
${ }^{7}$ We also used a second approach to inference and report p-values from this alternative in Appendix Table 9 for the baseline estimates. Specifically, we used the distribution of the ratio of the post-expansion mean squared prediction error (MSPE) to the pre-expansion MSPE from the placebo analyses to evaluate the statistical significance of estimates (Abadie et al. 2010). We found a relatively low correlation between the magnitude of the post-period difference (our key estimate of interest) and the MSPE ratio. This finding reflects the fact that the MSPE ratio considers only the difference of the post-to-pre prediction error and is somewhat more in the spirit of a differencein-difference estimator than the synthetic control approach. In addition, the MSPE is a relative (proportional) difference that can differ dramatically from absolute differences. So, many small and economically unimportant (post) estimates may seem "unusual" (significant) based on the proportional differences of the MSPE ratio. The main advantage of the MSPE is that it incorporates the "quality" of the experiment (matching), but we show results for alternate matching approaches to address this issue.
} 
areas with the largest fraction of residents who are uninsured and in households earning under 138 percent of the FPL. In the ACS, the smallest geographic area available is the Public Use Microdata Area (PUMA). We therefore order all PUMAs based on the fraction of residents who are uninsured and low income, and include only the top quartile of PUMAs in our analysis. The sample for this analysis is adults ages 19 to 64 .

\section{Consumer Credit Panel/Equifax}

We use information from the Federal Reserve Bank of New York Consumer Credit Panel/Equifax (CCP) data to measure the financial outcomes of the population between the ages of 19-64. The CCP is a quarterly database containing data from one (Equifax) of the three major credit bureaus. Credit bureaus maintain records for all individuals who apply for credit. The data we use covers all adults with a social security number who have ever applied for any type of credit. We use the nationally representative 5\% sample of the CCP data. These data have been used to study the credit market effects of other social programs, for example, unemployment insurance (Hsu, Matsa, and Melzer 2014). Our age restriction is designed to ensure that our sample is representative of the adult population below age $65 .^{8}$ The resulting sample consists of about 8 million records per quarter.

We use all quarters of data from 2010 through 2015, giving us four years of data prior to the Medicaid expansion and two years of data post-expansion. The CCP contains no socioeconomic information and the only demographic information is birth year. However, there is detailed geographic information including zip code of residence. We utilize the information on age and geography in order to focus on individuals in the income ranges targeted by the Medicaid expansions, namely $138 \%$ or less of the FPL. Specifically, we used estimates from the 2008-2012 American Community Survey (ACS) of the share of a zip code adult population under age 65 who are both uninsured and have an income less than

\footnotetext{
${ }^{8}$ Although low-income adults often use informal credit such as payday loans (Agrawal et al., 2009), most individuals have had some interaction with credit markets. For example, the Oregon Medicaid Experiment matched $68.5 \%$ of adults earning under the FPL to a credit report. In ongoing work with administrative data from Michigan we have matched $90.1 \%$ percent of Medicaid enrollees to credit bureau data.
} 
$138 \%$ of the FPL to select the sample. ${ }^{9}$ We selected individuals living in the quartile of zip codes with the highest shares of people that were both uninsured and had income less than $138 \%$ of the FPL. We refer to this sample as the "most treated." This includes about 8,100 zip codes covering all states. On average, $17 \%$ of persons in these zip codes were uninsured and had incomes less than $138 \%$ of the FPL. In our CCP sample, there are approximately 1.8 million individual records in the top quartile of zip code per quarter. The unit of observation for our analysis is state-by-quarter.

In some analyses, we stratify the sample by age in order to evaluate heterogeneous effects of the Medicaid expansions by age. Young individuals are less likely to experience a serious illness, so they may be less likely to be affected by the Medicaid expansions. However, young individuals are also more likely to be uninsured, and experienced larger coverage gains as a result of the Medicaid expansion (see Appendix Table 4). Analyzing the data separately by age allows us to document any differential effects due to age. Thus, we divided the sample into three age groups: 19 to 32 , 33 to 44, and 45 to 64 .

Although the CCP database consists of over 600 potential indicators of financial wellbeing based on the various forms of debt and account line information (e.g., credit cards, mortgages, auto loans, etc.), we purposefully restricted our attention to only a limited number of measures that a priori we thought most suitable. Our choices were based on the following general considerations: we preferred broad, aggregate measures to narrow ones; we selected outcomes likely to have been quickly affected by a health shock (and therefore, ameliorated by access to insurance); and where possible, considered outcomes that are unambiguous in terms of their welfare consequences. Our variables include: the total amount of debt (excluding mortgage debt); the total amount of debt at least 30 days past due; credit card debt; credit card debt past due; the number of new third party collections (all types, including medical) in the last 12 months; the total balance of collections in the last 12 months; bankruptcy in past 24 months; and the

\footnotetext{
${ }^{9}$ See http://www.census.gov/acs/www/data/data-tables-and-tools/data-profiles/. The American Community Survey provides small area (i.e., zip codes) estimates of uninsured in the five-year data file. We used the 2008-2012 file. The ACS includes an indicator of whether a person is below 138\% of FPL and provides health insurance information. For this analysis we are forced to use the 18-64 age range in order to obtain ACS estimates at the zip code level.
} 
credit score. ${ }^{10,11}$ We note that some of the financial outcomes we selected represent accumulated balances, or "stocks” (e.g., total amount of debt), and some are time-specific and represent "flows” (e.g., collections in the last 12 months). Since we are evaluating changes in these variables over time, and because we selected variables that respond within relatively short time periods to external events, such as health insurance coverage, we expect to have sufficient statistical power to detect effects of Medicaid expansions. One possible exception is credit score, which is based only partially on delinquency and debt behavior and may therefore be slower to respond. In addition to our collections variables, our other measures of debt may include medical debt. For example, a patient may use his or her credit card to pay for medical care or prescription drugs.

Previous studies, notably the Oregon Health Insurance Experiment (Baicker et al., 2013; Finkelstein et al., 2012), highlighted how access to insurance had a relatively quick effect in reducing unpaid medical balances reported to third-party collection agencies within a year of the reform. Dobkin et al. (2017) also showed that non-medical collections increased significantly in the first year after a hospitalization, and Barcellos and Jacobson (2015) also found relatively rapid responses of collection balances to insurance coverage. There is less evidence that the other selected financial indicators will respond within two years, although Dobkin et al. (2017) reported that credit card balances and credit limits decreased significantly within one year of hospitalization for both insured and uninsured persons,

\footnotetext{
${ }^{10}$ Our understanding of what is captured in the collections variable in the CCP is different than in previous drafts of the paper. Data documentation files and conversations with Equifax representatives previously led us to believe that medical debt was not included in the collections variable. To verify this claim, we purchased an extract from Equifax containing disaggregated collection measures for a subsample of our data for a single quarter. This extract provided information on categories of collections including, medical, auto, retail, and other categories. We then merged this extract onto the CCP and compared the disaggregated collection measures to the aggregated collection variable used in our paper. Some simple analysis made it very clear that the CCP does indeed contain all collection subcategories including medical debt.

${ }^{11}$ Although credit cards are a specific category of debt, we thought to include it separately since it is a common source of credit for our population of interest. We also included the credit score, even though it may be slow to adjust to financial shocks because it is a useful summary measure of credit access. For total amount of debt (past due), we excluded amounts from first mortgage trades, home equity installment trades, and home equity revolving trades. Total (credit card) debt at least 30 days past due excludes trades currently in bankruptcy and includes trades currently 30 days past due, 60 days past due, 90 days past due, 120 days past due or in collections, and severe derogatory. Detailed description of all the outcome variables can be found in the Appendix.
} 
while Mazumder and Miller (2016) found reductions in credit market delinquencies and bankruptcies one year following the expansion of coverage through the Massachusetts health care reform.

In addition to information on financial outcomes from the CCP, we use data on state demographic and socioeconomic characteristics, which are used in the synthetic control method to match treatment and control states. To capture changing economic conditions at the state level during the pre-reform period from 2010 to 2013, we use annual state poverty rate from the Small Area Income and Poverty Estimates (SAIPE) produced by the U.S. Census Bureau, annual state unemployment rate from the U.S. Bureau of Labor Statistics, and annual state $25^{\text {th }}$ and $75^{\text {th }}$ percentile of the log wage distribution for adults 19-64, calculated using the March Current Population Survey (CPS). We also construct a measure of Medicaid eligibility using the 2010 March CPS sample to capture the share of adults 19-64 that would be eligible for Medicaid in each state and year. ${ }^{12}$ Additionally, we aggregate zip code level demographics data to the state level to capture the population characteristics in the top quartile of uninsured-low-income quartile zip codes. Specifically, we use the 2012, five-year ACS estimates of the following: share of zip code nonelderly adult population Hispanic; share of zip code non-elderly adult population Black; and share of zip code non-elderly adult population with a high school diploma or less. ${ }^{13}$

Finally, because the CCP data allow us to follow the same adult over time, we can examine the potential for endogenous migration patterns by fixing a person's state and zip code of residence at the 2013 location, which is immediately prior to the Medicaid expansion. Results are largely unchanged when we restrict the sample in this way and we verify that our estimates are not sensitive to the year in which we assign state and zip code of residence (see Appendix Table 6). Moreover, recent evidence specific to Medicaid (Schwartz and Sommers, 2014) suggests that there is no evidence that low-income individuals

\footnotetext{
${ }^{12}$ We obtain the Medicaid eligibility thresholds from the 2010-2013 Kaiser Family Foundation's annual reports on Medicaid eligibility rules. (See http://kff.org/medicaid/report/annual-updates-on-eligibility-rules-enrollment-and/.) We use the March 2010 CPS to calculate whether each individual aged 19-64 is eligible for Medicaid for each year from 2010 to 2013, given the state of residence, total household income, work status in the past year, and number of children. For simulated Medicaid eligibility, we match on the average pre-2014 values because there is virtually no change in eligibility over this period.

${ }^{13}$ These calculations use persons 18-64 years old because these estimates are available from the ACS at the zip code level.
} 
moved in response to past Medicaid expansions. Similarly, evidence on whether low-income persons moved for AFDC/TANF benefits also suggest little migration (Kaestner et al., 2003).

\section{Assigning States to Treatment and Control Groups}

As a result of the U.S. Supreme Court ruling on Medicaid (National Federation of Independent Business v. Sebelius), states were given the option of expanding Medicaid to cover all adults with incomes less than or equal to $138 \%$ of the FPL beginning in 2014. As of the end of 2015, 29 states and the District of Columbia had expanded Medicaid (in some form) while 21 states had not. For our analysis, however, the classification of treatment and control states differs from this simple distinction.

First, Delaware, Massachusetts, New York, Vermont, and Washington D.C. fully expanded Medicaid to parents and childless adults prior to 2014; we place them in the control group since they were effectively untreated in 2014 and 2015 and did not change status. ${ }^{14}$ Second, there were seven states that expanded Medicaid under the ACA (Arizona, California, Connecticut, Hawaii, Iowa, Minnesota, and Washington) and two states (Maine and Wisconsin) that did not opt to expand under the ACA that had partially expanded Medicaid to the low-income adult population in some significant way prior to $2014 .^{15}$ These nine states that were "prior expanders" pose the largest challenge for classification. To address this issue, we consider two samples: (1) a broad sample where we include these nine states (seven in the treatment group and 2 in the control group) and (2) a narrow sample that drops these nine states from the analysis. ${ }^{16}$ Finally, since we define the treatment period as the eight quarters spanning from the first quarter of 2014 through the last quarter of 2015, we cannot include four “late expander” states (Alaska, New Hampshire, Pennsylvania, and Indiana) directly in our main analysis because they expanded after the

\footnotetext{
${ }^{14}$ Results are similar if we drop these states; see Appendix Table 12.

${ }^{15}$ We base this classification on Garrett and Kaestner (2015). It is worth noting that an additional six states that expanded Medicaid under the ACA (Colorado, Illinois, Maryland, New Jersey, Oregon, and Rhode Island) and one state (Tennessee) that did not expand under the ACA also had partial Medicaid expansions but their pre-2014 expansions were sufficiently minor in importance to be reasonably ignored. There is considerable variation in these earlier state expansions in terms of coverage (e.g., parents and/or childless adults), benefits (e.g., outpatient only) and generosity (income eligibility). More detailed information can be found in Heberlein et al., 2011 and Heberlein et. al. 2012.

${ }^{16}$ We also estimate results using a partially treated sample that includes only the seven states with pre-ACA expansions in the treated group.
} 
beginning of the treatment period. ${ }^{17}$ Recall that the synthetic control approach requires constructing a comparison group by matching on common, pre-policy outcomes, which necessitates a sharp temporal distinction between the treatment and control groups. Therefore, we cannot exploit all of the monthly variation in the timing of the ACA Medicaid expansions.

Thus, for our broad sample we have 21 states in the treatment group, 26 states in the control group, and 4 late expander states excluded. In our narrow sample, we have 14 states in the treatment group, 24 states in the control group, and 13 states excluded (9 partial expanders and 4 late expanders excluded). Appendix Table 1 shows how we classify the states.

In addition to the main analysis, we estimate the effects on the four late expanders as a separate group, using the first quarter of 2015 as the implementation date. We present two versions of this analysis in the appendix (Appendix Table 7): all four late expanders grouped together, and only Indiana and Pennsylvania included. We do not find evidence of significant improvement among these states, possibly due to the short post-expansion period.

\section{Results}

\section{Selecting Weights}

The synthetic control approach first requires the selection of weights to construct the comparison group. The weights are chosen to minimize differences in pre-2014 outcomes and covariates between states that did and did not expand Medicaid. We match on each pre-2014 value of the dependent variable and covariates; an alternative weighting method that matches on the pre-2014 average and 2013 values of the dependent variable, and each pre-2014 value of covariates is reported in the Appendix. ${ }^{18}$

\footnotetext{
${ }^{17}$ Although Michigan did not expand in the beginning of 2014, we do not drop them since their expansion started by 2014:Q2. The classification error in the case of Michigan is likely to be small.

${ }^{18}$ We also estimated models using (1) only the average pre-treatment dependent variable along with covariates and (2) only using the 2013 lagged value of the dependent variable along with covariates and obtained similar results.
} 
Table 1 presents the results of the matching procedure for one dependent variable: total collection balance in past 12 months. ${ }^{19}$ We show the means for treated states, means for control states (unweighted), and means for the synthetic control states. The most notable result is the close match between the preperiod (2014) means of the total collection balance between the treated states and the synthetic control states. In contrast, the pre-2014 means for the treated and control states (unweighted) are considerably different. The close tracking of the pre-2014 means between the treated states and the synthetic control states bolsters the case for the credibility of the research design and the interpretation of estimates from it as causal.

\section{Estimates of the Effect of Medicaid Expansions on Insurance Coverage}

We first document that the Medicaid expansions had a significant impact on insurance coverage. Although this has been shown in other studies (e.g, Black and Cohen 2015; Kaestner et al., 2017;

Sommers 2014; Wherry and Miller 2016; Miller and Wherry 2017), we replicate the results here using the synthetic control method and a similar sample to obtain a first-stage estimate in a manner consistent with our reduced form analysis. The results are reported in Appendix Table 3, and Appendix Table 4 reports the results by age group. We find that individuals living in the most-treated areas (i.e., highest share uninsured and low income PUMAs) in expansion states experienced an increase in insurance coverage of approximately 5 percentage points and an increase in Medicaid coverage of between 5 and 6 percentage points. We do not find statistically significant changes in the fraction of individuals reporting they have private insurance, indicating that crowd-out was likely minimal in these locations. These estimates are similar to those in other studies.

\section{Estimates of the Effect of Medicaid Expansions on Consumer Financial Wellbeing}

Figure 1 shows the time series for all eight indicators of financial wellbeing for our broad sample of treated states where we match on all pre-2014 values of the dependent variable and covariates. As can

\footnotetext{
${ }^{19}$ In Appendix Table 2, we provide the weights for each potential control state that were used to construct the synthetic control states for all seven dependent variables used in the analysis for the broad sample. Many states get zero weights.
} 
be seen in Figure 1, the pre-2014 time trends in the financial indicators are extremely close for the treated and synthetic control groups for most outcomes. ${ }^{20}$ This graphical evidence strongly supports the validity of the synthetic control research design. There is some divergence in the levels of the number of collections prior to the Medicaid expansions, but even here the trend in collections is quite similar for the treated and control groups. There is a slight divergence in the total collections balance just prior to the treatment. In 2013, the average difference between the treated and control unit means is \$23 with the largest difference of $\$ 39$, which is considerably smaller than the post-period divergence. Our estimates based on a simple DiD specification (Appendix Table 10) which explicitly takes into account this small divergence in 2013 yields very similar results. ${ }^{21}$ Similarly, Figure 2 shows trends in financial indicators for the narrow sample of treated states. Here too, pre-2014 trends in financial indicators between the treatment and control groups are very similar.

In terms of impact of Medicaid expansions, Figures 1 and 2 show that, at least through the end of 2015, there appears to be little or no effect of the Medicaid expansions on most indicators of financial wellbeing. The exceptions are the two outcomes related to bills reported to third-party collection agencies: there was a clear, substantial decline in the amount of balances in collections in the treated states relative to the synthetic control unit, and a relative, but less marked decline in the number of bills sent to collections in treated states.

Table 2 presents synthetic control estimates and $p$-values of the average post-2014 differences in outcomes between treatment and control groups corresponding to Figures 1 and $2 .{ }^{22}$ For each outcome, we also show the pre-reform means for the treated states. We use bold typeface to indicate estimates that remain statistically significant at the 5 percent level after adjusting our inference using the HolmBonferroni correction (Holm 1979). This correction controls the probability of a false positive within a

\footnotetext{
${ }^{20}$ The vertical line in the figures is drawn between the last pre-treatment period and the first post-treatment period.

${ }^{21}$ We also note that the triple difference estimates shown in Table 5 that take into account variation across zip codes, which also may control somewhat for pre-period divergence in collections, are also very similar to our main estimates.

${ }^{22}$ Estimates based on our alternative matching procedure for constructing the synthetic control group are in Appendix Table 5.
} 
domain of outcomes to be less than the significance level (in our case, 0.05). However, this correction is overly conservative (i.e., it fails to reject a false null hypothesis too frequently) unless outcomes are independent—-which is not the case in our context. ${ }^{23}$

We begin the discussion of results with credit score (row 1), which is a summary measure of credit-worthiness that largely governs an individual's access to credit. The results suggest that the Medicaid expansion had little effect on credit scores, as estimates in Table 2 (and Appendix Table 5) with respect to this outcome are very small. ${ }^{24}$

Row 2 presents the results for total debt excluding mortgage liabilities. Recall that the effect of the Medicaid expansion on debt is theoretically ambiguous. Estimates in row 2 indicate that the Medicaid expansions reduced total debt. Both estimates are negative and the estimate of the effect of the Medicaid expansion on total debt for the narrow group of treated states (-\$441) is marginally significant. Analogous estimates obtained using an alternative matching method (Appendix Table 5) are also negative, larger, and statistically significant before applying the Holm-Bonferroni correction. Overall, there appears to be some evidence that the Medicaid expansions reduced total debt, although the estimates are sensitive to the method of matching and whether we apply the Holm-Bonferroni correction. It is important to note that the mean value of total debt masks considerable variation between those individuals who are likely to be affected by the Medicaid expansions and those who are not. Those who are likely affected by the Medicaid expansion have debt levels that are likely to be considerably lower than average. For example, for those living in the most treated zip codes (top quartile of zip codes ranked by un-insurance and income less than $138 \%$ of the FPL), the pre-2014 mean of total debt is $\$ 10,341$ (column 1 of Table 2). The corresponding figure for those living in the least treated zip codes is significantly higher at $\$ 16,898$ (column 1 of Table 4). However, even this approximately \$6,500 difference likely underestimates the difference between those likely and unlikely to be affected by the Medicaid expansions because there are

\footnotetext{
${ }^{23}$ Because of the computationally intensive way our p-values are calculated, it is not feasible for us to use more powerful family-wise error rate controls that rely on bootstrapping such as those described in Anderson (2008). ${ }^{24}$ Difference-in-difference estimates in Appendix Table 10 are of the same magnitude as estimates in Table 2.
} 
both high- and low-income individuals in both samples. These differences imply that simply comparing the coefficient to the pre-Medicaid expansion mean may not be an accurate approach to assessing the magnitude of the effects. In addition, we may have less power to detect significant changes for some debt measures because the group affected by the Medicaid expansion has a relatively smaller impact on the average total debt.

Table 2 also presents the results for total debt past due (row 3). Estimates of the post-2014 difference between the treated and synthetic control states are small relative to the mean, and not statistically significant. Estimates in Appendix Table 5 are similar. Again, we note that for the group likely affected by Medicaid, the mean and standard deviation are expected to be considerably above the mean for the sample because income and past due debt are negatively correlated. The pre-2014 mean of total debt past due for individuals in the most treated zip code in the broad sample is $\$ 1,537$. This is about $25 \%$ more than the corresponding figure for individuals in the least treated zip codes of $\$ 1,153$ (see Tables 2 and 4). Moreover, the \$1,537 value constitutes a much higher fraction of total debt (about 15\%) than is the $\$ 1,153$ (about $6 \%$ ). The heterogeneity in the amount of debt and past due debt by income level implies that for measures of delinquent debt, we have relatively more statistical power. Nevertheless, estimates of the effect of the Medicaid expansions on amount past due are not close to being statistically significant.

In row 4 of Table 2, we present estimates of the effect of the Medicaid expansions on total credit card debt. Estimates are negative and not statistically significant, and, except for one, estimates in Appendix Table 5 obtained using the alternative matching method are similar. Estimates of the effects of the Medicaid expansions on credit card debt past due (row 5) are also negative, but not statistically significant.

The two outcomes in rows 6 and 7 of Table 2 relate to bills that are past due and sent to thirdparty collection agencies: the number of collections and the total amount of collections. The estimated effects on the amount of collections (row 6) are negative and statistically significant. Two out of four estimates remain statistically significant even after accounting for multiple testing. The effect sizes range 
from $-\$ 65$ to $-\$ 88$. Estimates in Appendix Table 5 obtained using the alternative matching procedure are very similar. Similarly, estimates of the effect of the Medicaid expansions on the number of accounts in collection (row 7) are also all negative and statistically significant (at 0.01 level or better). Estimates range from -0.038 to -0.045 . It is worth noting that difference-in-differences estimates pertaining to these outcomes in Appendix Table 10 are very similar to those in Table 2 and statistically significant. In the partially treated group of states (Appendix Table 5), we find somewhat smaller point estimates for both collection variables.

The significant decreases in the collection balance post-2014 is consistent with the expectation that expanded Medicaid coverage would reduce the debt burden of those who obtain coverage. It is larger than the estimated reduction in average collection amounts associated with the Massachusetts health care reform of -\$12 (Mazumder and Miller 2016), which may reflect that the population affected by the Medicaid expansion is more disadvantaged than the one affected by the Massachusetts reform. It is also consistent with Dobkin et al. (2017), who found that hospitalization among the uninsured led to increased collection balances for both medical and non-medical bills. Our estimates describe the average effect of Medicaid in the entire post-2014 period. However, it is clear from Figures 1 and 2 that the effect becomes larger over time. In Appendix Table 8, we report the year-by-year estimates. Consistent with the visual evidence in Figures 1 and 2, we find larger effects in 2015 (Panel B) than in 2014 (Panel A), indicating the effect of Medicaid is increasing over time.

The last outcome we examine is bankruptcy. Estimates related to this outcome are in the last row of Table 2. The estimate for the broad sample of treated states is -0.002 ( $8 \%$ of the mean) and marginally significant, and the estimate for the narrow group of treated states is virtually zero. Estimates in Appendix Table 5 are similar. Therefore, we conclude that the Medicaid expansions did not have a significant effect on bankruptcy.

The estimates described above capture the overall change in financial outcomes among the sample of adults with a credit report living in our target zip codes. However, only a fraction of these individuals actually obtained health insurance coverage through the ACA Medicaid expansions. Using 
ACS data, we estimate that in the most treated areas, Medicaid enrollment increased by about 5.7 percentage points (see Appendix Table 3). Focusing on the broad treatment group and the match using each value of the dependent variable, we find a treatment-on-treated (TOT) estimate of the effect of expansions on total debt in collection of $-\$ 1,140$ (-\$65/0.057). In the Oregon study (Finkelstein et. al. 2012), the mean amount of total collections (combining medical and non-medical) was $\$ 4,739$. Thus, our TOT estimate indicates a reduction in total collections of about 25 percent. In Oregon, the TOT for total collection balance was $\mathbf{- \$ 4 9 9}$. We note, however, that Medicaid enrollment is often measured with considerable error in surveys; discrepancies between survey and administrative records typically range from 10 to 35 percent (Call et al. 2013). Measurement error in reported Medicaid coverage results in attenuation and, as a result, can bias our treatment effect estimate upward (Hausman, Abrevaya and ScottMorton 1998; Meyer and Mittag 2014). This may explain in part why our estimated treatment effect is considerably larger than that reported in Finkelstein et al. (2012). Another possible explanation of the difference between our estimate and Finkelstein et al. (2012) is due to heterogeneous responses for those in our sample vis-à-vis the Oregon sample.

We also consider a second TOT calculation for uninsured individuals who are likely to face serious illness requiring hospitalization or emergency room admission. Here we used the National Health Interview Survey (NHIS) from 2010 through 2013 and found that 22\% of adults under the age of 65 who were uninsured with household incomes under 138\% of the FPL had experienced either a hospitalization or an ER visit in the last year. If we further rescale our earlier TOT estimates to apply to just individuals who had such an experience (1.25\%), the effects of gaining Medicaid among those with a serious health event is about $\$ 5,183$. This TOT estimate is the effect of acquiring health care insurance for those with a serious medical incident and assumes that individuals without a serious medical incident experienced no beneficial financial effects due to acquiring coverage. Dobkin et al. document that the impact of a hospitalization on total unpaid collections for uninsured individuals is approximately $\$ 6,200$, quite close to our estimated effect. Overall, our estimates in Table 2 suggest that the Medicaid expansions substantially improved the financial wellbeing of those who gained coverage by reducing the number of 
collections and amount of debt in third-party collections. There was also some evidence of a reduction in total debt.

We also conducted analyses on samples stratified by age to examine whether the effects of the Medicaid expansions differed by age group. There may be differences in income, health, and/or preferences that may affect both the probability of obtaining Medicaid and household finances. Columns (1) to (3) of Table 3 presents estimates of the effect of Medicaid on the each of the financial indicators for each of three age groups: a) 19-32 year olds, b) 33-44 year olds, and c) 45-64 year olds using our broad sample; columns (4) to (6) presents estimates for our narrow sample. Appendix Figures 2 through 4 present graphical evidence corresponding to estimates in columns (1) to (3) and Appendix Figures 5 through 7 show the corresponding charts for columns (4) through (6). The pre-2014 trends (and levels) for the outcomes are virtually the same for the treated and synthetic control states in nearly every case.

In Table 3, across all panels, we find fairly consistent evidence that the Medicaid expansions decreased the number of collections and the total amount of debt in third-party collection across all age groups. This finding is consistent with the increases in Medicaid coverage for all groups that are similar in size and only slightly larger for the youngest age group (see Appendix Table 4). For the 21 states in the broad sample of treated states, we find statistically significant reductions in collection balance for all age groups even when we apply the Holm-Bonferroni correction. Magnitudes for this sample range from $-\$ 71$ to $-\$ 104$. We also find that the expansions were associated with similar sized reductions in the number of collections for all age groups, but estimates are less consistently significant. We also find similar results for the narrow group of treated states. Overall, the estimates in Table 3 suggest that the financial benefits of the Medicaid expansions were experienced by all age groups.

\section{Tests of Validity of Research Design}

Although the consistent similarity of the pre-2014 trends for treated and synthetic control states in all of our figures provide substantial evidence of a valid research design, we conducted two additional 
analyses to further bolster the credibility of our approach. ${ }^{25}$ First, we conducted analyses using a sample of individuals living in what we consider the least treated zip codes, those in the lowest quartile of zip codes ranked according to the proportion of individuals who are both uninsured and have incomes below $138 \%$ of FPL. According to the ACS, only about $2 \%$ of individuals in the least treated zip codes would be expected to have been eligible for the Medicaid expansions. Therefore, we expect this group to be much less affected by the Medicaid expansions overall.

Figure 3 shows the time series patterns of outcomes for treated and synthetic control states (selected for this sample) for the least treated zip codes of the broad sample of treated states. During the treatment period, the Medicaid expansions had little effect on the non-collections outcomes. We also find evidence of reductions in the number of collections and in collection balances for the least treated zip codes, but the differences between the treatment and synthetic control groups are not nearly as large as those in Figure $1 .{ }^{26}$ We expect the effect to be small because relatively few individuals are affected, although those who are affected are likely to have a relatively large influence on the mean of total collections because of the strong association between income and third-party collections.

Estimates in Table 4, which have the same format as in Table 2, are consistent with the graphical evidence. The estimates on the number of collections are small and not statistically significant. Similarly, the effects on collection balances are also much lower than they were when estimated with the highest treatment group. The fact that estimates are significantly lower in the areas less likely to be treated provides further validation of the synthetic control research design.

Second, we incorporate these least-affected zip codes directly into our analysis by estimating a triple difference model that uses these zip codes as an additional source of variation in the effect of the expansion. These results are reported in Table 5. As expected from the models that estimate the effects on the most and least treated zip codes separately, we find similar results in the triple difference model as in

\footnotetext{
${ }^{25}$ The close match of pre-trends between the treatment and synthetic control groups is found for alternative methods of selecting weights, which provides additional support for the validity of the research design (see, for example, Appendix Figures 12-14).

${ }^{26}$ It is also important to take into account the different scales for the y-axis between Figure 1 and Figure 3.
} 
our main specification for the broad and narrow sample of states, with statistically significant reductions in collections of between $-\$ 50$ and $-\$ 89$ and in the number of collections of between -0.043 and -0.046 .

The third assessment of our research design consisted of analyses using a sample of individuals over age 65 living in the most treated zip codes. Almost all of these individuals are covered by Medicare and should not be affected by the Medicaid expansions, which explicitly target those under age 65 . The Medicaid eligibility rules for those over 65 (dual eligible) were not altered by the ACA, although they may have been affected by the expansion indirectly, for example, if a family member gained coverage. Table 6 provides estimates for those over age 65 and Figure 4 presents the graphical evidence corresponding to Table 6 estimates in column 2. Estimates in Table 6 suggest that the Medicaid expansions decreased the total balance (-\$337) and total collections balance (-\$19) of the elderly. However, these estimates are not robust to the method of matching. Analogous estimates obtained using the alternative method of matching are not statistically significant and much smaller in magnitude. ${ }^{27}$ Overall, these estimates provide additional validation of the synthetic control research design.

\section{Estimates of the Effect of Medicaid on the Distribution of Outcomes}

In addition to evaluating the impact of Medicaid eligibility on the mean of financial outcomes, we also examine how the ACA Medicaid expansions affected the distribution of these outcomes. This analysis can be suggestive of underlying mechanisms. For example, if we find that the ACA expansions prevented collections of small amounts among a large group of individuals, this would suggest that Medicaid coverage improves financial outcomes through widespread and diffuse income effects. Alternatively, if we find an impact on large collections concentrated among a small number of individuals, this would suggest that Medicaid mostly improves financial outcomes by protecting individuals who experience very large medical expenses from significant health shocks.

\footnotetext{
27 Results are available upon request. In relative terms, estimates in Table 6 for total balance (-\$337) and total collections balance (-\$19) represent effect sizes of $6 \%$ and $21 \%$ respectively.
} 
To examine how Medicaid affects delinquencies of different sizes, we created four categories for each of our delinquency outcomes (total amount past due, total credit card debt past due, and total collections). ${ }^{28}$ For total amount past due, we created categories indicating whether the individual had $\$ 0$ past due, $\$ 1-5,000$ past due, $\$ 5,001-10,000$ past due and more than $\$ 10,000$ past due. For credit card debt past due and total amount in collections, we used lower thresholds as the amounts are generally much smaller than total amount past due (see Table 2). We created variables indicating \$0 in collections or credit card delinquency respectively, $\$ 1-1,000$ in collections or credit card delinquency, $\$ 1,001-\$ 2,000$ in collections or credit card delinquency, and more than $\$ 2,000$ in collections or credit card delinquency.

In addition to delinquency measures, we also examine the effects on the distribution of credit scores. Since credit scores summarize an individual's creditworthiness, changes in the credit score distribution may capture effects not quantified by the delinquency measures described above. For credit score, we created variables indicating a credit score less than or equal to 600, between 601 and 660, between 661 and 780, and above 780. These bins roughly correspond to ratings of bad, poor, fair/good, and excellent credit used by creditors. We applied the Holm-Bonferroni correction within each set of outcomes (i.e., we adjusted for the fact we were conducting 4 tests in each category).

Table 7 presents estimates of the effect of Medicaid on these categories of debt and credit score. While there are several statistically significant findings among the many estimates, the most consistent estimates are those pertaining to a large collection balance. In this case, estimates indicate a reduction in the probability of having a collection balance of $\$ 2000$ or more. Estimates indicate that individuals in the most treated zip codes in the 21 Medicaid expansions states experienced a reduction in the probability of having a large amount in collection by about 0.4 percentage points. Estimates pertaining to the stratified sample of treated states are similar in magnitude. Before applying the Holm-Bonferroni correction, all estimates are statistically significant at .10 level or less. These estimates suggest that the overall reduction

\footnotetext{
${ }^{28}$ We selected thresholds based on the distribution of the outcomes using data from 2010-2013. For example, for total debt past due, $\$ 4000$ is the median for people with balance past due and $\$ 10,000$ is the $75^{\text {th }}$ For credit card debt past due, $\$ 2,000$ is the median for people with credit card balance and $\$ 6,000$ is the $75^{\text {th }}$ percentile.
} 
in collections observed in previous tables is largely being driven by large reductions in collections consistent with the elimination of large medical bills.

\section{Conclusion}

The financial protection provided by health insurance is arguably its most important function. This is particularly true in the case of Medicaid because of the relatively high prevalence of disease among low-income individuals and the substantial financial burden that illness imposes on those who become seriously ill or injured. Indeed, a major justification for the Affordable Care Act was to provide such financial protection. In this study, we examined whether the recent expansion of Medicaid to individuals aged 19-64 as part of the ACA affected the financial wellbeing of persons living in lowincome zip codes. Ours is the first national study of the effect of expanding Medicaid to these individuals on several measures of financial wellbeing.

We used high-quality data from a large panel of credit reports from the Federal Reserve Bank of New York Consumer Credit Panel/Equifax. To obtain estimates of the effect of the Medicaid expansions on financial wellbeing, we employed the synthetic control approach of Abadie et al. (2010). We provide evidenced that the approach was likely valid, so estimates of the effect of the Medicaid expansion are plausibly interpreted as causal.

Results indicated that the Medicaid expansions significantly reduced the amount of debt in thirdparty collection among individuals living in the top quartile of zip codes ranked by the proportion of poor and uninsured persons. Intention-to-treat (ITT) estimates indicated that the 2014 Medicaid expansions were associated with a reduction in the amount of collections of between $\$ 65$ and $\$ 88$. These reduced form estimates imply a treatment-on-treated (TOT) effect of approximately $\$ 1,140$. For other measures of debt and debt past due, we did not find any consistent evidence that the ACA Medicaid expansions had any effect, although it would be useful to revisit these estimates as more years of post-expansion data become available. 
While these results show that the ACA Medicaid expansions had important financial impacts outside of health care use, they are also consistent with recent work documenting that much of the incidence of these financial effects falls on third parties, as much as the uninsured themselves (Finkelstein et al., 2015; Garthwaite, Gross, and Notowidigdo, 2018; Nikpay et al., 2017). Given that the ACA Medicaid expansions decreased unpaid bills, the financial benefits of the ACA expansions extend, at least partially, to organizations that extend credit to low-income uninsured individuals, as these creditors are less likely to be adversely impacted by bad debt. As a result, it may be easier to obtain credit or increase borrowing among those individuals who gained coverage through the ACA Medicaid expansions, which may improve their material wellbeing in the future. 


\section{References}

Abadie, A., A. Diamond, and J. Hainmueller. 2010. Synthetic Control Methods for Comparative Case Studies: Estimating the Effect of California’s Tobacco Control Program. Journal of the American Statistical Association 105 (490):493-505.

Agarwal, S., P. Skiba, and J. Tobacman. 2009. Payday Loans and Credit Cards: New Liquidity and Credit Scoring Puzzles? American Economic Review 99(2): 412-417.

Anderson, M. 2008. Multiple Inference and Gender Differences in the Effects of Early Intervention: A Reevaluation of the Abecedarian, Perry Preschool, and Early Training Projects. Journal of the American Statistical Association 103(484):1481-1495.

Baicker, K., Taubman, S., Allen, H., Bernstein M., Gruber, J., Newhouse, J., Schneider, E., Wright, B., Zaslavsky, A., Finkelstein, A., and the Oregon Health Study Group. 2013. The Oregon Experiment Effects of Medicaid on Clinical Outcomes New England Journal of Medicine 368:1713-22.

Barcellos, S. and M. Jacobson (2015). The effects of Medicare on medical expenditure risk and financial strain. American Economic Journal: Economic Policy 7(4):41-70.

Billmeier A, Nannicini T. 2013. Assessing Economic Liberalization Episodes: A Synthetic Control Approach. The Review of Economics and Statistics. 95(3):983-1001.

Black, L. and Cohen, R. Insurance Status by State Medicaid Expansion Status: Early Release Estimates from the National Health Interview Survey, 2013-September 2014. National Center for Health Statistics. 2015. Available at: http://www.cdc.gov/nchs/nhis/releases.htm, accessed on September 15, 2015.

Barone G, Mocetti S. 2014. Natural Disasters, Growth and Institutions: A Tale of Two Earthquakes. Journal of Urban Economics. 84:52-66.

Brevoort, K., Grimm, P. and M. Kambara. 2015. Data Point: Credit Invisibles. Consumer Financial Protection Bureau Office of Research.

Kenneth P. Brevoort, Daniel Grodzicki, and Martin Hackmann. 2017. Medicaid and Financial Health. NBER Working Paper \#24002, Cambridge: Ma.

Buchmueller, T., Levinson, Z., Levy, H., and B. Wolfe. 2016. Effect of the Affordable Care Act on Racial and Ethnic Disparities in Health Insurance Coverage. American Journal of Public Health. 106(8):14161421.

Call, K., Davern, M., Klerman, J. and V. Lynch. 2013. Comparing Errors in Medicaid Reporting across Surveys: Evidence to Date. Health Services Research 48(2):652-664.

Centers for Medicare \& Medicaid Services. Medicaid \& CHIP: October 2014 Monthly Applications, Eligibility Determinations and Enrollment Report 2014. Available at: http://www.medicaid.gov/medicaidchip-program-information/program- information/downloads/october-2014-enrollment-report.pdf, accessed November 30, 2015.

Cunningham, P. 2008. Trade-Offs Getting Tougher: Problems Paying Medical Bills Increase for U.S. Families, 2003-2007, Tracking Report No. 21. Available at:

http://www.hschange.com/CONTENT/1017/?PRINT=1\#ib2, accessed on December 30, 2015. 
Dobkin, A., Finkelstein, A., Kluender, R., and M. Notowidigdo. 2017. The Economic Consequences of Hospital Admissions. Unpublished working paper, Massachusetts Institute of Technology.

Doty, M., S. Collins, S. Rustgi, and J. Kriss. 2008. Seeing Red: The Growing Burden of Medical Bills and Debt Faced by U.S. Families. The Commonwealth Fund Issue Brief.

Eren O, Ozbeklik, S. 2016. What Do Right-to-Work Laws Do? Evidence from a Synthetic Control Method Analysis. Journal of Policy Analysis and Management. 35(1): 173-194.

Finkelstein, A., Hendren, N., and E. Luttmer. 2015. The Value of Medicaid: Interpreting Results from the Oregon Health Insurance Experiment. NBER Working Paper No. 21308.

Finkelstein, A., S. Taubman, B. Wright, M. Bernstein, J. Gruber, J. Newhouse, H. Allen, K. Baicker, and the Oregon Health Study Group. 2012. The Oregon Health Insurance Experiment: Evidence from the First Year. Quarterly Journal of Economics 127(3):1057-1106.

Garthwaite, C., Gross, T., and M. Notowidigdo. 2018. Hospitals as Insurers of Last Resort. forthcoming, AEJ: Applied Economics. 10(1):1-39.

Garrett, B. and R. Kaestner. 2014. The Best Evidence Suggests the Effects of the ACA on Employment Will Be Small. Urban Institute Brief.

Gross, T. and M. Notowidigdo. 2011. Health insurance and the consumer bankruptcy decision: Evidence from expansions of Medicaid. Journal of Public Economics 97 (7-8): 767-778.

Gross, T., Notowidigdo, M., and J. Wang. 2014. Liquidity Constraints and Consumer Bankruptcy: Evidence from Tax Rebates. Review of Economics and Statistics, 96(3): 431-443.

Gruber, J. and A. Yelowitz. 1999. Public Health Insurance and Private Savings. Journal of Political Economy 107(6):1249-1274.

Hausman J, Abrevaya J, Scott-Morton F. 1998. Misclassification of the Dependent Variable in a DiscreteResponse Setting. Journal of Econometrics. 87(2):239-269.

Heberlein, M., Brooks, T., Guyer, J., et al. Holding Steady, Looking Ahead: Annual Findings of a 50State Survey of Eligibility Rules, Enrollment and Renewal Procedures, and Cost Sharing Practices in Medicaid and CHIP, 2010-2011. Menlo Park, CA: Kaiser Family Foundation, 2011.

Heberlein, M., Brooks, T., Guyer, J., et al. Performing Under Pressure: Annual Findings of a 50-State Survey of Eligibility, Enrollment, Renewal, and Cost-Sharing Policies in Medicaid and Chip, 2011-2012. Menlo Park, CA: Kaiser Family Foundation, 2012, https://kaiserfamilyfoundation files.wordpress.com/2013/01/8272.pdf

Holm, S. (1979). "A simple sequentially rejective multiple test procedure". Scandinavian Journal of Statistics. 6 (2): 65-70

Hsu, J. D. Matsa and B. Melzer. 2014. Positive Externalities of Social Insurance: Unemployment Insurance and Consumer Credit. NBER Working Paper No. 20353. 
Kaestner, R., B. Garrett, A. Gangopadhyaya, and C. Fleming. 2017. Effects of Medicaid Expansions on Health Insurance Coverage and Labor Supply. Journal of Policy Analysis and Management. 36(3):493738.

Kaestner, R., N. Kaushal, and G. Van Ryzin. 2003. Migration Consequences of Welfare Reform. Journal of Urban Economics, 53:357-376.

Kaiser Family Foundation. Annual Updates on Eligibility Rules, Enrollment and Renewal Procedures, and Cost-Sharing Practices in Medicaid and CHIP, December 2009 - January 2013. Kaiser Family Foundation, 2013. Available at: http://kff.org/medicaid/report/annual-updates-on-eligibility-rulesenrollment-and, accessed on March 17, 2016.

Kaul, A., Kloßner, S., and P. Gregor, and M. Schieler. 2015. Synthetic Control Methods: Never Use All Pre-Intervention Outcomes as Economic Predictors. Unpublished manuscript Saarland University. Available at:http://www.oekonometrie.uni-saarland.de/papers/SCM_Predictors.pdf, accessed December 30, 2015.

Leininger, L., H. Levy, and D. Schanzenbach. 2012. Consequences of SCHIP Expansions for Household Wellbeing Forum for Health Economics \& Policy 13.1.

Mazumder, B. and S. Miller. 2016. The Effect of the Massachusetts Reform on Financial Wellbeing. American Economic Journal: Economic Policy 8(3):284-313.

Meyer B, Mittag N. 2014. Misclassification in Binary Choice Models. NBER Working Paper \#20509.

Miller S, Wherry LR. 2017. Health and access to care during the first 2 years of the ACA Medicaid expansions. New England Journal of Medicine 376:947-956.

Nikpay S.. Buchmueller T, Levy H, Singh R.. The Relationship Between Uncompensated Care and Hospital Financial Position: Implications of the ACA Medicaid Expansion for Hospital Operating Margins The Journal of Healthcare Finance. 2016 Dec;43(2). 72-89.

Nunez, S., K. Schaberg, R. Hendra, L. Servon, M Addo and A. Mapillero-Colomina, 2016. Online Payday and Installment Loans: Who Uses Them and Why? A Demand-Side Analysis from Linked Administrative, Survey, and Qualitative Interview Data, MDRC.

Schwartz, A. L., and B. D. Sommers. 2014. Moving For Medicaid? Recent Eligibility Expansions Did Not Induce Migration From Other States. Health Affairs, vol. 33 no. 1 88-94

Sommers

Sommers, B.D. 2014. Insurance Cancellations in Context: Stability of Coverage in the Nongroup Market Prior to Health Reform. Health Affairs, vol. 33 no. 5 887-894.

Wherry, L and S. Miller. 2016. Early Coverage, Access, Utilization, and Health Effects of the Affordable Care Act Medicaid Expansions: A Quasi-Experimental Study. Annals of Internal Medicine 164(12):795803 
Table 1

Comparison of Pre-2014 Means for Treated States and Synthetic Control States

Dependent Variable is Total Collection Balance; 21 Treatment States, 26 Potential Control States

\begin{tabular}{|c|c|c|c|}
\hline & Treated States & Control States & Synthetic Control States \\
\hline & $(1)$ & $(2)$ & (3) \\
\hline $\begin{array}{l}\text { State Simulated Medicaid } \\
\text { Eligibility }\end{array}$ & 0.080 & 0.035 & 0.102 \\
\hline \multicolumn{4}{|l|}{ State Unemployment Rate } \\
\hline 2010 & 0.108 & 0.094 & 0.097 \\
\hline 2011 & 0.101 & 0.087 & 0.092 \\
\hline 2012 & 0.090 & 0.076 & 0.085 \\
\hline 2013 & 0.081 & 0.068 & 0.075 \\
\hline \multicolumn{4}{|l|}{ State Poverty Rate } \\
\hline 2010 & 0.158 & 0.173 & 0.162 \\
\hline 2011 & 0.166 & 0.180 & 0.170 \\
\hline 2013 & 0.167 & 0.178 & 0.170 \\
\hline 2013 & 0.165 & 0.176 & 0.169 \\
\hline \multicolumn{4}{|l|}{ State 25th Percentile of Log Wage } \\
\hline 2010 & 9.66 & 9.71 & 9.75 \\
\hline 2011 & 9.70 & 9.74 & 9.77 \\
\hline 2012 & 9.70 & 9.74 & 9.75 \\
\hline 2013 & 9.76 & 9.81 & 9.84 \\
\hline \multicolumn{4}{|l|}{ State 75th Percentile of Log Wage } \\
\hline 2010 & 10.93 & 10.84 & 10.93 \\
\hline 2011 & 10.95 & 10.87 & 10.93 \\
\hline 2012 & 10.96 & 10.87 & 10.94 \\
\hline 2013 & 10.99 & 10.90 & 10.95 \\
\hline \% Hispanic & $37.0 \%$ & $24.8 \%$ & $21.6 \%$ \\
\hline$\%$ Black & $15.6 \%$ & $24.4 \%$ & $23.0 \%$ \\
\hline \% HS Degree or Less & $29.4 \%$ & $28.3 \%$ & $28.3 \%$ \\
\hline \% Uninsured \& <138\% FPL & $15.9 \%$ & $16.6 \%$ & $15.3 \%$ \\
\hline Average Total Collection Balance & 333.08 & 479.69 & 330.34 \\
\hline \multicolumn{4}{|l|}{ Total collection balance } \\
\hline 2010Q1 & 320.65 & 426.74 & 294.39 \\
\hline 2010Q2 & 335.59 & 443.37 & 302.04 \\
\hline 2010Q3 & 328.47 & 452.59 & 307.58 \\
\hline 2010Q4 & 313.62 & 448.69 & 311.91 \\
\hline 2011Q1 & 312.05 & 442.19 & 307.31 \\
\hline 2011Q2 & 320.05 & 459.68 & 314.34 \\
\hline 2011Q3 & 326.15 & 465.59 & 320.93 \\
\hline 2011Q3 & 331.11 & 479.38 & 334.29 \\
\hline 2012Q1 & 345.71 & 479.17 & 339.22 \\
\hline 2012Q2 & 354.62 & 496.47 & 346.49 \\
\hline 2012Q3 & 347.88 & 488.42 & 324.19 \\
\hline 2012Q4 & 355.32 & 519.92 & 351.91 \\
\hline 2013Q1 & 341.96 & 519.59 & 355.71 \\
\hline 2013Q2 & 340.37 & 512.96 & 347.79 \\
\hline 2013Q3 & 322.44 & 509.20 & 355.15 \\
\hline $2013 Q 4$ & 333.26 & 535.89 & 372.28 \\
\hline
\end{tabular}


Table 2

Synthetic Control Estimates of the Effect of Medicaid on Indicators of Financial Wellbeing Persons Living in Most Treated Zip Codes, Ages 19-64

\begin{tabular}{|c|c|c|c|c|}
\hline \multirow[b]{2}{*}{ Outcome } & \multicolumn{2}{|c|}{$\begin{array}{c}21 \text { Treatment States } \\
26 \text { Potential Control States }\end{array}$} & \multicolumn{2}{|c|}{$\begin{array}{c}14 \text { Treatment States } \\
24 \text { Potential Control States }\end{array}$} \\
\hline & $\begin{array}{c}\text { Pre-Reform } \\
\text { Mean in Treated } \\
\text { States } \\
\text { (Std. Dev.) } \\
\text { (1) }\end{array}$ & $\begin{array}{c}\text { Estimates } \\
\text { (p-value) } \\
(2)\end{array}$ & $\begin{array}{c}\text { Pre-Reform } \\
\text { Mean in Treated } \\
\text { States } \\
\text { (Std. Dev.) } \\
\text { (3) }\end{array}$ & $\begin{array}{c}\text { Estimates } \\
\text { (p-value) } \\
(4)\end{array}$ \\
\hline \multirow[t]{2}{*}{ Credit Score } & 648 & 1 & 643 & -1 \\
\hline & (13) & $(0.554)$ & $(15)$ & $(0.245)$ \\
\hline \multirow[t]{2}{*}{ Total Balance } & 10341 & -221 & 10636 & $-441 *$ \\
\hline & $(1278)$ & $(0.241)$ & (1613) & $(0.054)$ \\
\hline \multirow[t]{2}{*}{ Total Balance Past Due } & 1537 & 29 & 1451 & 39 \\
\hline & $(271)$ & $(0.488)$ & $(240)$ & $(0.455)$ \\
\hline \multirow[t]{2}{*}{ Total Credit Card Balance } & 2580 & -26 & 2455 & -61 \\
\hline & (397) & $(0.405)$ & $(434)$ & $(0.103)$ \\
\hline \multirow[t]{2}{*}{ Total Credit Card Balance Past Due } & 855 & -24 & 676 & -3 \\
\hline & (315) & $(0.347)$ & (238) & $(0.891)$ \\
\hline \multirow[t]{2}{*}{ Total Collections Balance in Past 12 Months } & 333 & $-65 * * *$ & 394 & $-88 * * *$ \\
\hline & $(105)$ & $(0.000)$ & $(107)$ & $(0.000)$ \\
\hline \multirow[t]{2}{*}{ Number of Collections in Past 12 Months } & 0.461 & $-0.045^{* * *}$ & 0.591 & $-0.038 *$ \\
\hline & $(0.177)$ & $(0.008)$ & $(0.141)$ & $(0.063)$ \\
\hline \multirow[t]{2}{*}{ Bankruptcy in Past 24 Months } & 0.024 & $-0.002 *$ & 0.024 & 0.000 \\
\hline & $(0.005)$ & $(0.060)$ & $(0.006)$ & $(0.815)$ \\
\hline
\end{tabular}

Table 2 reports the estimates of the post-2014 differences in financial indicators between treated and synthetic control states for non-elderly adults in the most treated zip codes. The synthetic control weights are determined by matching on all values of the dependent variable in the pre-reform period. Columns (1) - (2) present the results for the broad sample with 21 treatment states and 26 potential control states. Columns (3) - (4) present the results for the narrow sample with 14 treatment states and 24 potential control states. For each expansionary definition, we present the 2010-2013 pre-reform mean outcome for the treated states and the average post-reform quarterly difference between the treated states and their synthetic counterpart. In all results, AK, IN, NH, and PA are dropped. Bolded results are also significant at the $5 \%$ level when the Holm-Bonferroni correction using 8 outcomes is applied to assess absolute gap p-values. Significance levels: $*=10 \%$, $* *=5 \%$, $* * *=1 \%$. 
Table 3

Synthetic Control Estimates of the Effect of Medicaid on Indicators of Financial Wellbeing for Persons Living in Most Treated Zip Codes by Age Group

\begin{tabular}{|c|c|c|c|c|c|c|}
\hline \multirow[b]{2}{*}{ Outcome } & \multicolumn{3}{|c|}{$\begin{array}{c}21 \text { Treatment States } \\
26 \text { Potential Control States }\end{array}$} & \multicolumn{3}{|c|}{$\begin{array}{c}14 \text { Treatment States } \\
24 \text { Potential Control States }\end{array}$} \\
\hline & $\begin{array}{c}\text { Ages 19- } \\
32 \\
(1) \\
\end{array}$ & $\begin{array}{c}\text { Ages 33- } \\
44 \\
(2)\end{array}$ & $\begin{array}{c}\text { Ages 45- } \\
64 \\
(3)\end{array}$ & $\begin{array}{c}\text { Ages 19- } \\
32 \\
(4)\end{array}$ & $\begin{array}{c}\text { Ages 33- } \\
44 \\
(5)\end{array}$ & $\begin{array}{c}\text { Ages 45- } \\
64 \\
(6)\end{array}$ \\
\hline \multirow[t]{2}{*}{ Credit Score } & 1 & $2 *$ & $2 *$ & -1 & 1 & 1 \\
\hline & $(0.363)$ & $(0.069)$ & $(0.059)$ & $(0.492)$ & $(0.679)$ & $(0.325)$ \\
\hline \multirow[t]{2}{*}{ Total Balance } & -203 & 8 & -135 & -250 & 222 & -151 \\
\hline & $(0.364)$ & $(0.972)$ & $(0.483)$ & $(0.213)$ & $(0.449)$ & $(0.544)$ \\
\hline \multirow[t]{2}{*}{ Total Balance Past Due } & 54 & -52 & $-128 * * *$ & 52 & 17 & 41 \\
\hline & $(0.297)$ & $(0.378)$ & $(0.009)$ & $(0.449)$ & $(0.832)$ & $(0.454)$ \\
\hline \multirow[t]{2}{*}{ Total Credit Card Balance } & -17 & -84 & $-167 * *$ & $-51^{*}$ & $-97 *$ & $-104 *$ \\
\hline & $(0.580)$ & $(0.105)$ & $(0.012)$ & $(0.091)$ & $(0.071)$ & $(0.052)$ \\
\hline \multirow[t]{2}{*}{ Total Credit Card Balance Past Due } & -11 & $-92 * *$ & $-89 * *$ & -9 & -8 & -13 \\
\hline & $(0.580)$ & $(0.019)$ & $(0.035)$ & $(0.611)$ & $(0.817)$ & $(0.692)$ \\
\hline \multirow[t]{2}{*}{ Total Collections Balance in Past 12 Months } & $-71 * * *$ & $-104 * * *$ & $-74 * * *$ & $-94 * * *$ & $-93 * * *$ & $-50 * *$ \\
\hline & $(0.004)$ & $(0.000)$ & $(0.001)$ & $(0.004)$ & $(0.010)$ & $(0.035)$ \\
\hline \multirow[t]{2}{*}{ Number of Collections in Past 12 Months } & $-0.044^{* *}$ & -0.036 & $-0.028 *$ & $-0.062 * *$ & $-0.059 * *$ & $-0.037 *$ \\
\hline & $(0.042)$ & $(0.172)$ & $(0.096)$ & $(0.023)$ & $(0.050)$ & $(0.068)$ \\
\hline \multirow[t]{2}{*}{ Bankruptcy in Past 24 Months } & -0.001 & -0.002 & $-0.002 *$ & 0.002 & 0.000 & -0.001 \\
\hline & $(0.447)$ & $(0.129)$ & $(0.098)$ & $(0.111)$ & $(0.737)$ & $(0.252)$ \\
\hline
\end{tabular}

Table 3 reports the estimates of the post-2014 differences in financial indicators between treated and synthetic control states by age group for the most treated zip code. The synthetic control weights are determined by matching on all values of the dependent variable in the pre-reform period. Columns (1) - (3) present the results for each age group in the broad sample with 21 treatment states and 26 potential control states. Columns (4) - (6) present the results for each age group in the narrow sample with 14 treatment states and 24 potential control states. For each age group, we present the average post-reform quarterly difference between the treated states and their synthetic counterpart. In addition to AK, IN, NH, and PA, DC and MA are dropped from all age results due to not having enough observations for many credit categories. HI is also dropped from ages 19-32 results. Bolded results are also significant at the $5 \%$ level when the Holm-Bonferroni correction using 8 outcomes is applied to assess absolute gap p-values. Significance levels: $*=10 \%, * *=5 \%, * * *=1 \%$. 
Table 4

Synthetic Control Estimates of the Effect of Medicaid on Indicators of Financial Wellbeing for Persons Living in Least Treated Zip Codes, Ages 19-64

\begin{tabular}{|c|c|c|c|c|}
\hline \multirow[b]{2}{*}{ Outcome } & \multicolumn{2}{|c|}{$\begin{array}{c}21 \text { Treatment States } \\
26 \text { Potential Control States }\end{array}$} & \multicolumn{2}{|c|}{$\begin{array}{l}14 \text { Treatment States } \\
24 \text { Potential Control States }\end{array}$} \\
\hline & $\begin{array}{c}\text { Pre-Reform } \\
\text { Mean in Treated } \\
\text { States } \\
\text { (Std. Dev.) } \\
\text { (1) }\end{array}$ & $\begin{array}{c}\text { Estimates } \\
\text { (p-value) } \\
\text { (2) }\end{array}$ & $\begin{array}{c}\text { Pre-Reform } \\
\text { Mean in Treated } \\
\text { States } \\
\text { (Std. Dev.) } \\
\text { (3) }\end{array}$ & $\begin{array}{c}\text { Estimates } \\
\text { (p-value) } \\
\text { (4) }\end{array}$ \\
\hline \multirow[t]{2}{*}{ Credit Score } & 719 & 1 & 718 & -1 \\
\hline & (8) & $(0.542)$ & (8) & $(0.306)$ \\
\hline \multirow[t]{2}{*}{ Total Balance } & 16898 & 178 & 17149 & $539 * *$ \\
\hline & $(1336)$ & $(0.237)$ & (1336) & $(0.018)$ \\
\hline \multirow[t]{2}{*}{ Total Balance Past Due } & 1153 & -48 & 1113 & -57 \\
\hline & $(235)$ & $(0.122)$ & $(159)$ & $(0.113)$ \\
\hline \multirow[t]{2}{*}{ Total Credit Card Balance } & 5326 & -61 & 5274 & $-246 * * *$ \\
\hline & $(583)$ & $(0.190)$ & $(492)$ & $(0.010)$ \\
\hline \multirow[t]{2}{*}{ Total Credit Card Balance Past Due } & 1992 & -31 & 1744 & 19 \\
\hline & $(746)$ & $(0.468)$ & $(407)$ & $(0.694)$ \\
\hline \multirow[t]{2}{*}{ Total Collections Balance in Past 12 Months } & 114 & -7 & 118 & 1 \\
\hline & (28) & $(0.263)$ & (30) & $(0.906)$ \\
\hline \multirow[t]{2}{*}{ Number of Collections in Past 12 Months } & 0.155 & 0.000 & 0.177 & 0.005 \\
\hline & $(0.057)$ & $(0.948)$ & $(0.059)$ & $(0.592)$ \\
\hline \multirow[t]{2}{*}{ Bankruptcy in Past 24 Months } & 0.017 & -0.000 & 0.017 & 0.000 \\
\hline & $(0.005)$ & $(0.629)$ & $(0.004)$ & $(0.434)$ \\
\hline
\end{tabular}

Table 4 reports the estimates of the post-2014 differences in financial indicators between treated and synthetic control states for non-elderly adults in the least treated zip codes. The synthetic control weights are determined by matching on all values of the dependent variable in the pre-reform period. Columns (1) - (2) present the results for the broad sample with 21 treatment states and 26 potential control states. Columns (3) - (4) present the results for the narrow sample with 14 treatment states and 24 potential control states. For each expansionary definition, we present the 2010-2013 pre-reform mean outcome for the treated states and average post-reform quarterly difference between the treated states and their synthetic counterpart. In all results, AK, IN, NH, and PA are dropped. Bolded results are also significant at the $5 \%$ level when the Holm-Bonferroni correction using 8 outcomes is applied to assess absolute gap p-values. Significance levels: $*=10 \%, * *=5 \%$, $* * *=1 \%$. 
Table 5

“Triple Difference” Estimates

Synthetic Control Estimate of Most Treated Zip Codes minus Synthetic Control Estimate of Least Treated Zip Codes

\begin{tabular}{|c|c|c|}
\hline & $\begin{array}{l}21 \text { Treatment States } \\
26 \text { Potential Control States }\end{array}$ & $\begin{array}{l}14 \text { Treatment States } \\
24 \text { Potential Control States }\end{array}$ \\
\hline \multirow[t]{2}{*}{ Outcome } & $\begin{array}{l}\text { Estimates } \\
\text { ( } p \text {-value) }\end{array}$ & $\begin{array}{l}\text { Estimates } \\
\text { ( } p \text {-value) }\end{array}$ \\
\hline & $(1)$ & $(2)$ \\
\hline \multirow[t]{2}{*}{ Credit Score } & -0 & -0 \\
\hline & $(0.999)$ & $(0.795)$ \\
\hline \multirow[t]{2}{*}{ Total Balance } & -399 & $-980 * * *$ \\
\hline & $(0.105)$ & $(0.000)$ \\
\hline \multirow[t]{2}{*}{ Total Balance Past Due } & 77 & 96 \\
\hline & $(0.166)$ & $(0.139)$ \\
\hline \multirow[t]{2}{*}{ Total Credit Card Balance } & 35 & $185 * *$ \\
\hline & $(0.460)$ & $(0.026)$ \\
\hline \multirow[t]{2}{*}{ Total Credit Card Balance Past Due } & 7 & -21 \\
\hline & $(0.877)$ & $(0.663)$ \\
\hline \multirow[t]{2}{*}{ Total Collections Balance in Past 12 Months } & $-57 * * *$ & $-89 * * *$ \\
\hline & $(0.004)$ & $(0.000)$ \\
\hline \multirow[t]{2}{*}{ Number of Collections in Past 12 Months } & $-0.046 * *$ & $-0.043 * *$ \\
\hline & $(0.012)$ & $(0.040)$ \\
\hline \multirow[t]{2}{*}{ Bankruptcy in Past 24 Months } & $-0.002 * *$ & -0.000 \\
\hline & $(0.050)$ & $(0.756)$ \\
\hline
\end{tabular}

Table 5 reports the estimates of the post-2014 differences in financial indicators between most and least treated zip codes for the treated and synthetic control states for non-elderly adults. The synthetic control weights are determined by matching on all values of the dependent variable in the pre-reform period. Column (1) presents the results for the broad sample with 21 treatment states and 26 potential control states. Column (2) presents the results for the narrow sample with 14 treatment states and 24 potential control states. For each expansionary definition, we present the average post-reform quarterly difference between the treated states and their synthetic counterpart. In all results, $\mathrm{AK}, \mathrm{IN}, \mathrm{NH}$, and PA are dropped. Bolded results are also significant at the $5 \%$ level when the Holm-Bonferroni correction using 8 outcomes is applied to assess absolute gap p-values. Significance levels: * $=10 \%$, $* *=5 \%, * * *=1 \%$. 
Table 6

Synthetic Control Estimates of the Effect of Medicaid on Indicators of Financial Wellbeing for Elderly in Most Treated Zip Codes, Ages 65 and Over

\begin{tabular}{|c|c|c|c|c|}
\hline \multirow{4}{*}{ Outcome } & \multicolumn{2}{|c|}{$\begin{array}{c}21 \text { Treatment States } \\
26 \text { Potential Control States }\end{array}$} & \multicolumn{2}{|c|}{$\begin{array}{l}14 \text { Treatment States } \\
24 \text { Potential Control States }\end{array}$} \\
\hline & Pre-Reform & & Pre-Reform & \\
\hline & $\begin{array}{c}\text { Mean in Treated } \\
\text { States } \\
\text { (Std. Dev.) }\end{array}$ & $\begin{array}{c}\text { Estimates } \\
\text { ( } p \text {-value) }\end{array}$ & $\begin{array}{c}\text { Mean in Treated } \\
\text { States } \\
\text { (Std. Dev.) }\end{array}$ & $\begin{array}{c}\text { Estimates } \\
\text { ( } p \text {-value) }\end{array}$ \\
\hline & $(1)$ & (2) & (3) & (4) \\
\hline \multirow[t]{2}{*}{ Credit Score } & 736 & 0 & 735 & -0 \\
\hline & $(12)$ & $(0.694)$ & (14) & $(0.751)$ \\
\hline \multirow[t]{2}{*}{ Total Balance } & 5349 & $-337 * *$ & 5349 & $-449 *$ \\
\hline & $(459)$ & $(0.037)$ & $(536)$ & $(0.053)$ \\
\hline \multirow[t]{2}{*}{ Total Balance Past Due } & 620 & -14 & 566 & 19 \\
\hline & $(153)$ & $(0.689)$ & $(135)$ & $(0.568)$ \\
\hline \multirow[t]{2}{*}{ Total Credit Card Balance } & 2510 & -42 & 2370 & $-128 * *$ \\
\hline & $(330)$ & $(0.313)$ & $(351)$ & $(0.017)$ \\
\hline \multirow[t]{2}{*}{ Total Credit Card Balance Past Due } & 872 & -22 & 740 & -3 \\
\hline & (288) & $(0.601)$ & $(262)$ & $(0.919)$ \\
\hline \multirow[t]{2}{*}{ Total Collections Balance in Past 12 Months } & 91 & $-19 * * *$ & 95 & -9 \\
\hline & $(27)$ & $(0.000)$ & (33) & $(0.234)$ \\
\hline \multirow[t]{2}{*}{ Number of Collections in Past 12 Months } & 0.145 & -0.003 & 0.172 & -0.002 \\
\hline & $(0.056)$ & $(0.634)$ & $(0.058)$ & $(0.776)$ \\
\hline \multirow[t]{2}{*}{ Bankruptcy in Past 24 Months } & 0.013 & $-0.001 *$ & 0.012 & -0.000 \\
\hline & $(0.004)$ & $(0.085)$ & $(0.004)$ & $(0.880)$ \\
\hline
\end{tabular}

Table 6 reports the estimates for the post-2014 differences in financial indicators between treated and synthetic control states for elderly adults in the most treated zip codes. The synthetic control weights are determined by matching on all values of the dependent variable in the pre-reform period. Columns (1) - (2) present the results for the broad sample with 21 treatment states and 26 potential control states. Columns (3) - (4) present the results for the narrow sample with 14 treatment states and 24 potential control states. For each expansionary definition, we present the 2010-2013 pre-reform mean outcome for the treated states and average postreform quarterly difference between the treated states and their synthetic counterpart. In addition to AK, IN, NH, and PA, DC and MA are dropped due to not having enough observations. Bolded results are also significant at the 5\% level when the HolmBonferroni correction using 8 outcomes is applied to assess absolute gap p-values. Significance levels: $*=10 \%$, $* *=5 \%$, $* * *=$ $1 \%$. 
Table 7

Synthetic Control Estimates of the Effect of Medicaid on the Distribution of Delinquencies and Credit Score

\begin{tabular}{|c|c|c|c|c|}
\hline \multirow[b]{2}{*}{ Outcome } & \multicolumn{2}{|c|}{$\begin{array}{c}21 \text { Treatment States } \\
26 \text { Potential Control States }\end{array}$} & \multicolumn{2}{|c|}{$\begin{array}{c}14 \text { Treatment States } \\
24 \text { Potential Control States }\end{array}$} \\
\hline & $\begin{array}{c}\text { Pre-Reform Mean in Treated } \\
\text { States } \\
\text { (Std. Dev.) } \\
\text { (1) }\end{array}$ & $\begin{array}{c}\text { Estimates } \\
\text { (p-value) } \\
(2)\end{array}$ & $\begin{array}{c}\text { Pre-Reform Mean in Treated } \\
\text { States } \\
\text { (Std. Dev.) } \\
\text { (3) }\end{array}$ & $\begin{array}{c}\text { Estimates } \\
\text { (p-value) } \\
(4)\end{array}$ \\
\hline \$0 Total Debt Past Due & $\begin{array}{c}0.807 \\
(0.023)\end{array}$ & $\begin{array}{l}-0.000 \\
(0.903)\end{array}$ & $\begin{array}{c}0.808 \\
(0.025)\end{array}$ & $\begin{array}{l}-0.005 \\
(0.140)\end{array}$ \\
\hline \$1-\$5000 Total Debt Past Due & $\begin{array}{c}0.114 \\
(0.013)\end{array}$ & $\begin{array}{l}-0.001 \\
(0.528)\end{array}$ & $\begin{array}{c}0.116 \\
(0.016)\end{array}$ & $\begin{array}{l}-0.002 \\
(0.107)\end{array}$ \\
\hline$\$ 5001-\$ 10000$ Total Debt Past Due & $\begin{array}{c}0.034 \\
(0.006)\end{array}$ & $\begin{array}{l}-0.000 \\
(0.992)\end{array}$ & $\begin{array}{c}0.032 \\
(0.005)\end{array}$ & $\begin{array}{l}0.002^{*} \\
(0.082)\end{array}$ \\
\hline \$10000+ Total Debt Past Due & $\begin{array}{c}0.046 \\
(0.009) \\
\end{array}$ & $\begin{array}{l}-0.000 \\
(0.904) \\
\end{array}$ & $\begin{array}{c}0.043 \\
(0.008) \\
\end{array}$ & $\begin{array}{c}0.001 \\
(0.361) \\
\end{array}$ \\
\hline$\$ 0$ Credit Card Balance Past Due & $\begin{array}{c}0.822 \\
(0.034)\end{array}$ & $\begin{array}{l}0.014^{*} \\
(0.051)\end{array}$ & $\begin{array}{c}0.838 \\
(0.033)\end{array}$ & $\begin{array}{l}0.010^{* *} \\
(0.023)\end{array}$ \\
\hline \$1-\$1000 Credit Card Balance Past Due & $\begin{array}{c}0.033 \\
(0.007)\end{array}$ & $\begin{array}{l}-0.001 \\
(0.269)\end{array}$ & $\begin{array}{c}0.034 \\
(0.009)\end{array}$ & $\begin{array}{l}-0.001 \\
(0.360)\end{array}$ \\
\hline \$1001-\$2000 Credit Card Balance Past Due & $\begin{array}{c}0.037 \\
(0.007)\end{array}$ & $\begin{array}{c}0.000 \\
(0.987)\end{array}$ & $\begin{array}{c}0.035 \\
(0.008)\end{array}$ & $\begin{array}{l}-0.002 \\
(0.282)\end{array}$ \\
\hline$\$ 2000+$ Credit Card Balance Past Due & $\begin{array}{c}0.080 \\
(0.022) \\
\end{array}$ & $\begin{array}{c}-0.008 * * * \\
(0.009)\end{array}$ & $\begin{array}{c}0.066 \\
(0.018) \\
\end{array}$ & $\begin{array}{r}-0.003 \\
(0.133) \\
\end{array}$ \\
\hline$\$ 0$ Collections & $\begin{array}{c}0.765 \\
(0.058)\end{array}$ & $\begin{array}{c}0.003 \\
(0.561)\end{array}$ & $\begin{array}{c}0.723 \\
(0.048)\end{array}$ & $\begin{array}{c}-0.000 \\
(0.990)\end{array}$ \\
\hline$\$ 1-\$ 1000$ Collections & $\begin{array}{c}0.160 \\
(0.036)\end{array}$ & $\begin{array}{c}0.005 \\
(0.152)\end{array}$ & $\begin{array}{c}0.185 \\
(0.031)\end{array}$ & $\begin{array}{c}0.006 \\
(0.130)\end{array}$ \\
\hline \$1001-\$2000 Collections & $\begin{array}{c}0.039 \\
(0.012)\end{array}$ & $\begin{array}{c}-0.004 * * \\
(0.021)\end{array}$ & $\begin{array}{c}0.048 \\
(0.011)\end{array}$ & $\begin{array}{c}-0.001 \\
(0.420)\end{array}$ \\
\hline$\$ 2000+$ Collections & $\begin{array}{c}0.036 \\
(0.012) \\
\end{array}$ & $\begin{array}{c}-0.004^{*} \\
(0.052) \\
\end{array}$ & $\begin{array}{c}0.044 \\
(0.011) \\
\end{array}$ & $\begin{array}{c}-0.007 * * \\
(0.013)\end{array}$ \\
\hline Credit Score $<=600$ & $\begin{array}{c}0.310 \\
(0.049)\end{array}$ & $\begin{array}{c}-0.001 \\
(0.823)\end{array}$ & $\begin{array}{c}0.328 \\
(0.053)\end{array}$ & $\begin{array}{l}-0.003 \\
(0.539)\end{array}$ \\
\hline Credit Score 601-660 & $\begin{array}{c}0.185 \\
(0.014)\end{array}$ & $\begin{array}{c}-0.007 * * \\
(0.013)\end{array}$ & $\begin{array}{c}0.177 \\
(0.009)\end{array}$ & $\begin{array}{c}-0.002 \\
(0.615)\end{array}$ \\
\hline Credit Score 661-780 & $\begin{array}{c}0.283 \\
(0.037)\end{array}$ & $\begin{array}{c}0.005 \\
(0.140)\end{array}$ & $\begin{array}{c}0.262 \\
(0.035)\end{array}$ & $\begin{array}{c}0.003 \\
(0.443)\end{array}$ \\
\hline Credit Score $780+$ & $\begin{array}{c}0.221 \\
(0.030)\end{array}$ & $\begin{array}{c}0.005 \\
(0.210)\end{array}$ & $\begin{array}{c}0.233 \\
(0.032)\end{array}$ & $\begin{array}{c}0.002 \\
(0.705)\end{array}$ \\
\hline
\end{tabular}

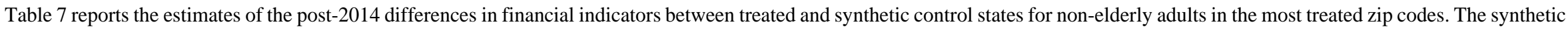

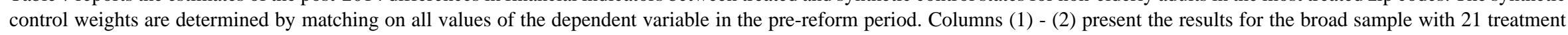




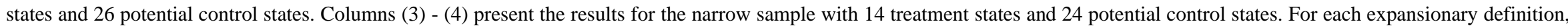

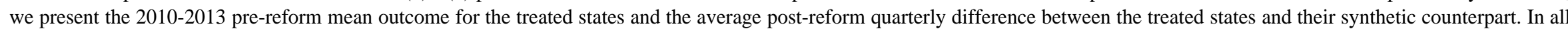

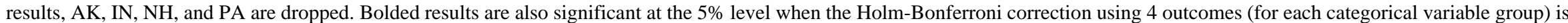
applied to assess absolute gap p-values. Significance levels: $*=10 \%, * *=5 \%$, $* * *=1 \%$. 


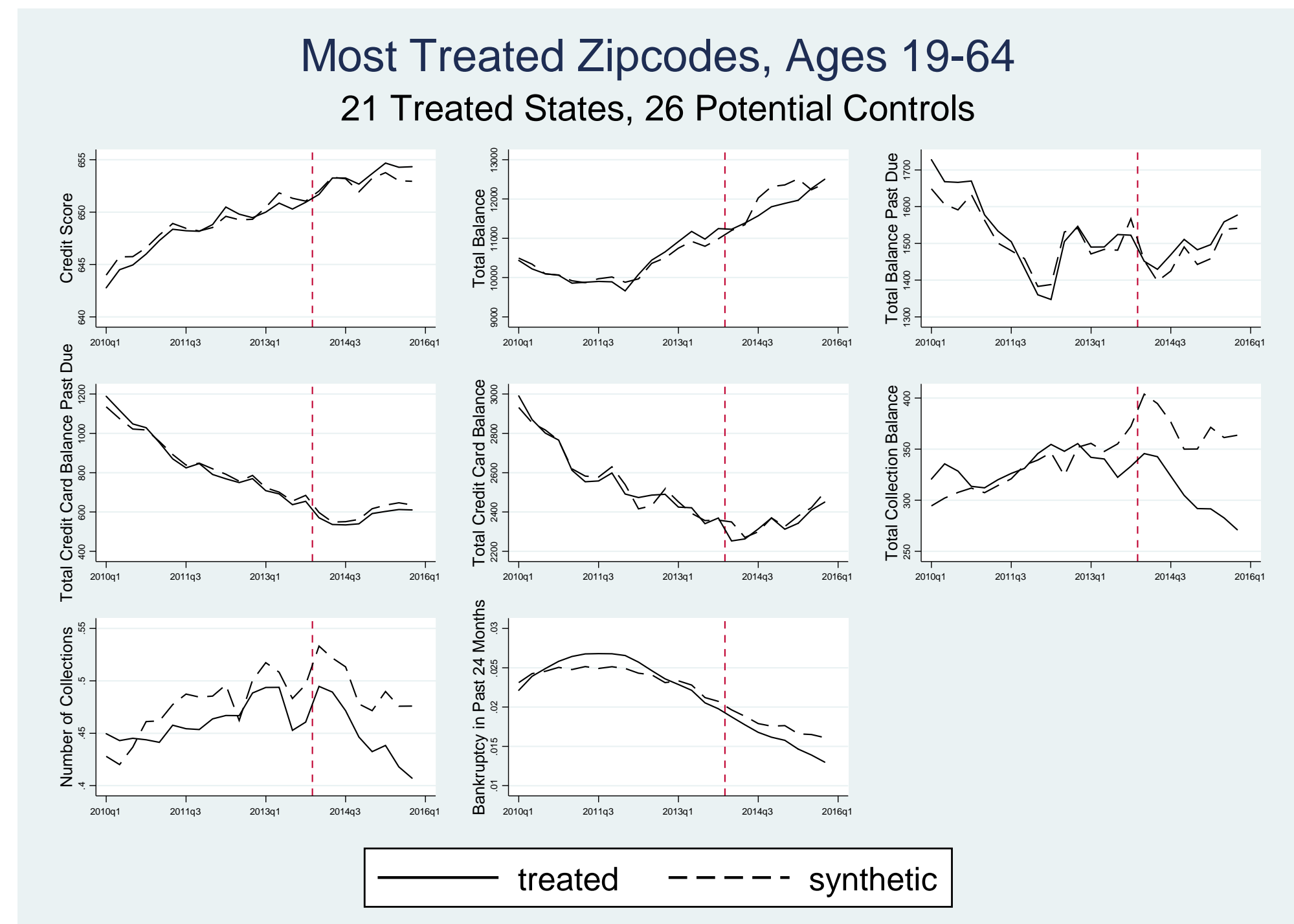

Figure 1. Synthetic Control Estimates of Effect of Medicaid Expansions on Indicators of Financial Wellbeing for Most Treated Zip Codes Using 21 Treated States, 26 Potential Control States 


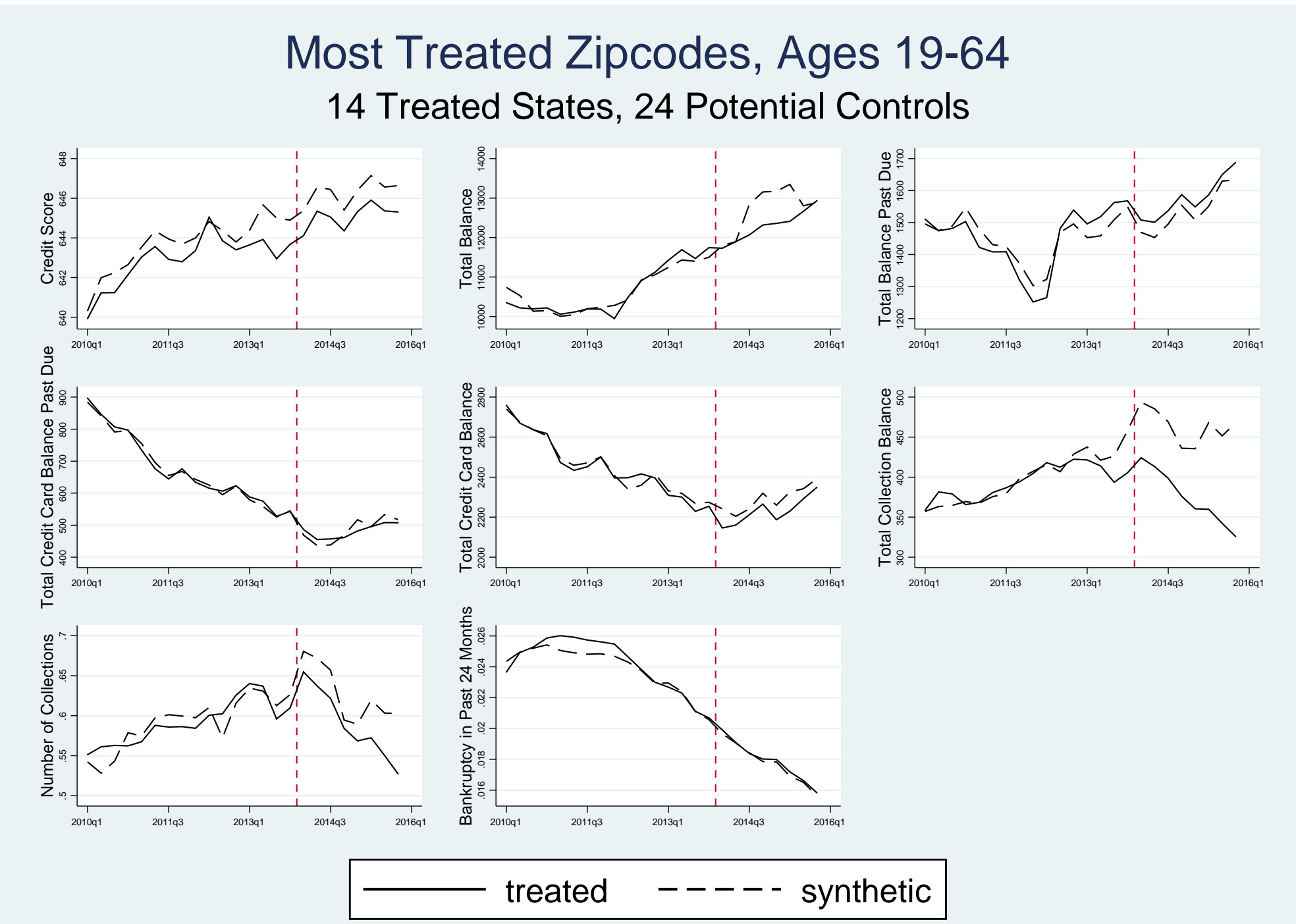

Figure 2. Synthetic Control Estimates of Effect of Medicaid Expansions on Indicators of Financial Wellbeing for Most Treated Zip Codes, Using 14 Treated States, 24 Potential Control States 


\section{Least Treated Zipcodes, Ages 19-64}

21 Treated States, 26 Potential Controls
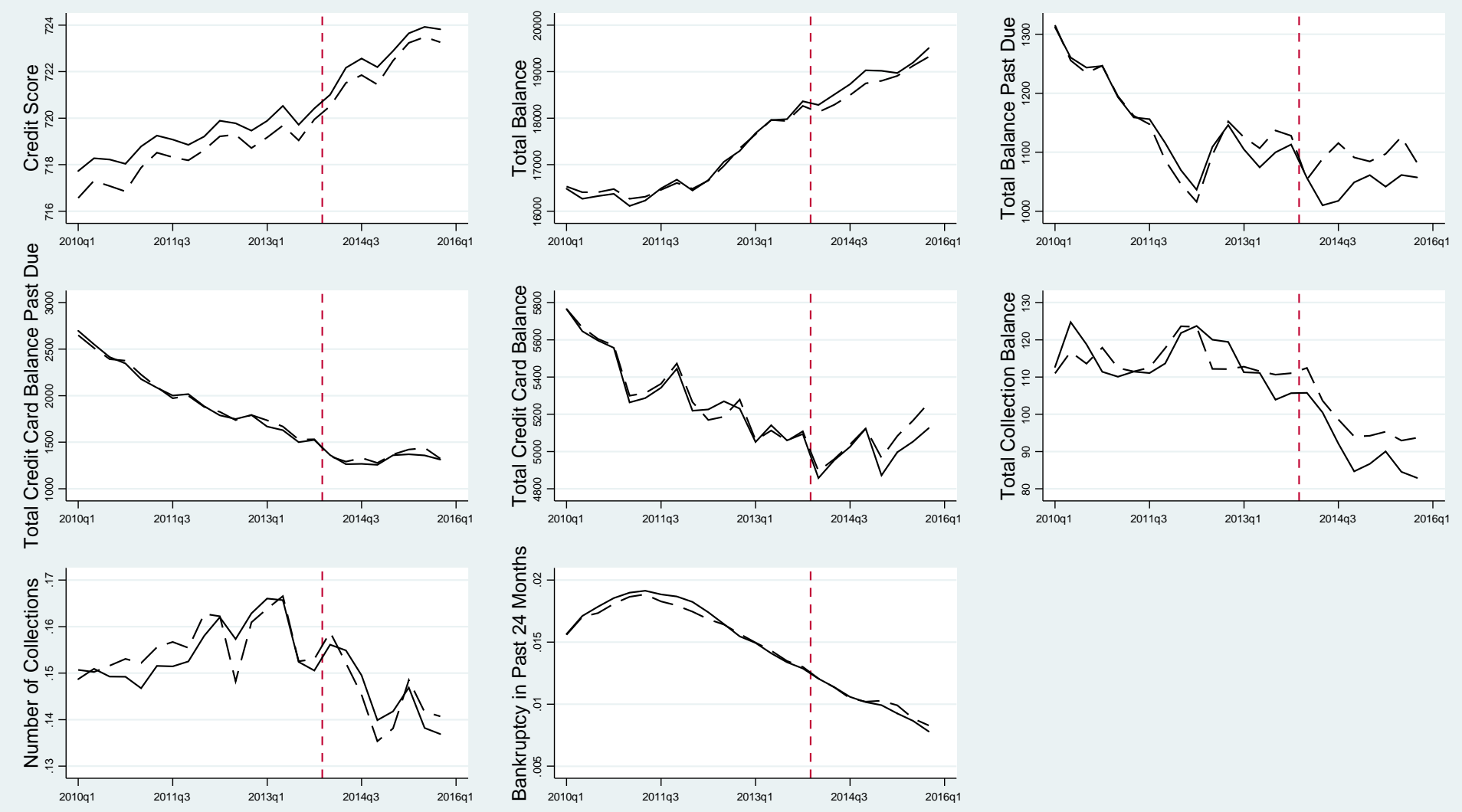

\section{treated - - - - synthetic}

Figure 3. Synthetic Control Estimates of Effect of Medicaid Expansions on Indicators of Financial Wellbeing for Least Treated Zip Codes Using 21 Treated States, 26 Potential Control States 


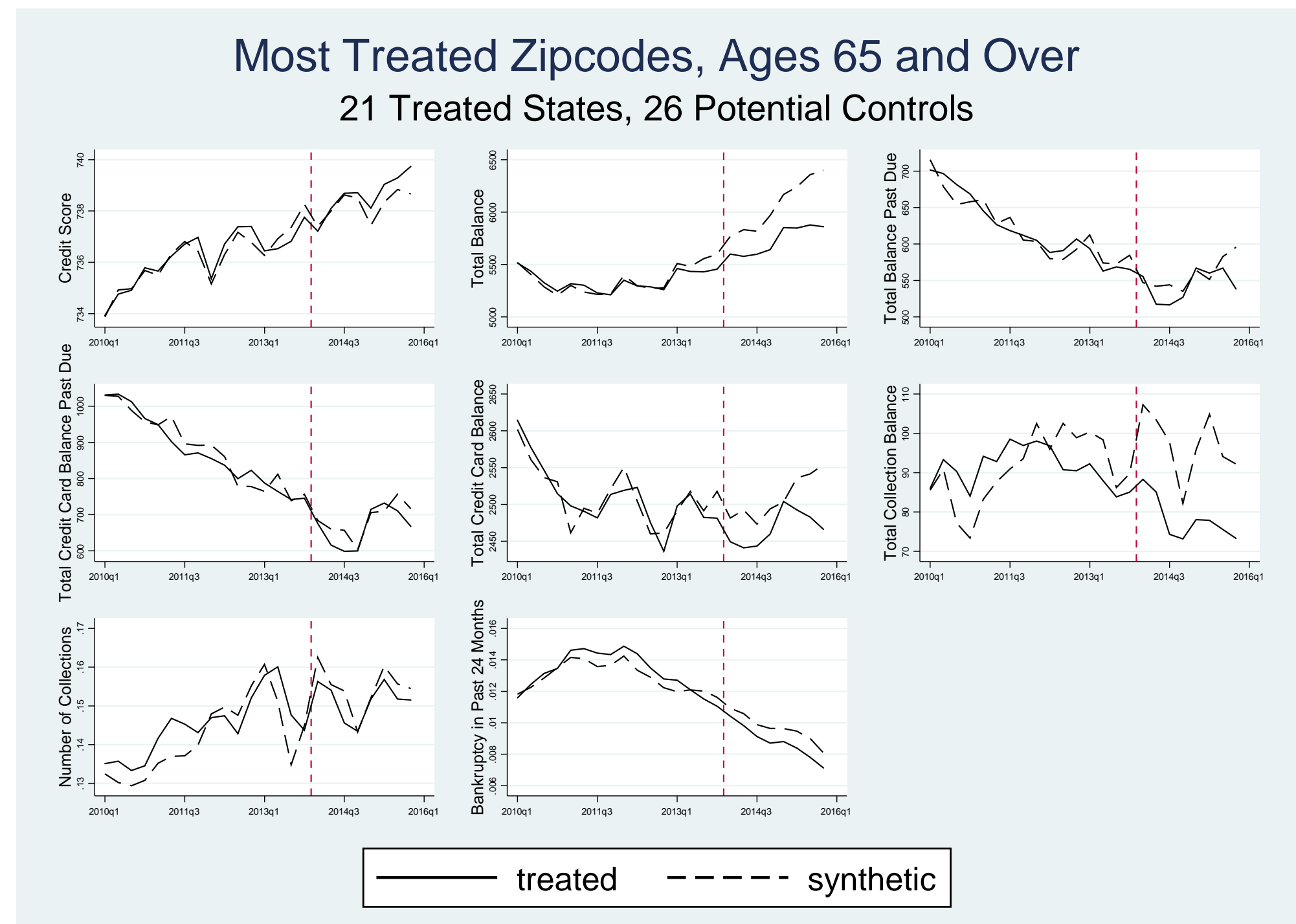

Figure 4. Synthetic Control Estimates of Effect of Medicaid Expansions on Indicators of Financial Wellbeing for Elderly in Most Treated Zip Codes Using 21 Treated States, 26 Potential Control State 